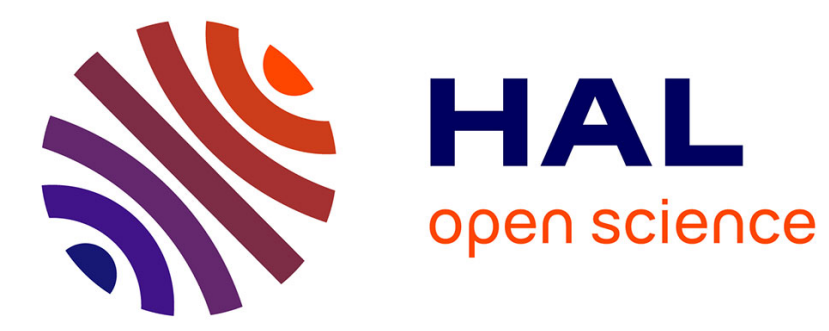

\title{
Set-based design by simulation of usage scenario coverage
}

Bernard Yannou, Pierre-Alain Yvars, Christopher Hoyle, Wei Chen

\section{To cite this version:}

Bernard Yannou, Pierre-Alain Yvars, Christopher Hoyle, Wei Chen. Set-based design by simulation of usage scenario coverage. Journal of Engineering Design, 2013, 33 p. 10.1080/09544828.2013.780201. hal-00801604v2

\section{HAL Id: hal-00801604 \\ https://hal.science/hal-00801604v2}

Submitted on 18 Mar 2013

HAL is a multi-disciplinary open access archive for the deposit and dissemination of scientific research documents, whether they are published or not. The documents may come from teaching and research institutions in France or abroad, or from public or private research centers.
L'archive ouverte pluridisciplinaire HAL, est destinée au dépôt et à la diffusion de documents scientifiques de niveau recherche, publiés ou non, émanant des établissements d'enseignement et de recherche français ou étrangers, des laboratoires publics ou privés. 


\title{
SET-BASED DESIGN BY SIMULATION OF USAGE SCENARIO COVERAGE
}

\author{
Bernard Yannou \\ Ecole Centrale Paris \\ Laboratoire Genie Industriel \\ Grande Voie des Vignes \\ 92290 Chatenay-Malabry, France \\ bernard.yannou@ecp.fr \\ Chris Hoyle \\ Oregon State University \\ School of Mechanical, Industrial, and \\ Manufacturing Engineering \\ 204 Rogers Hall \\ Corvallis, OR 97331, USA \\ chris.hoyle@oregonstate.edu
}

\author{
Pierre-Alain Yvars \\ Institut Supérieur de Mécanique de Paris \\ (SupMeca) - LISMMA \\ 3 rue Fernand Hainaut \\ 93407 Saint Ouen, France \\ payvars@supmeca.fr \\ Wei Chen \\ Northwestern University \\ Department of Mechanical Engineering \\ 2145 Sheridan Road \\ IL 60208-3111, USA \\ weichen@northwestern.edu
}

\begin{abstract}
While the marketing literature has advocated for decades that new products should be designed for intended and anticipated consumer usages, the engineering literature mostly proposes optimization of product performances independent of specific users' skills, anticipated usage scenarios, and competing products on the market. In contrast to tedious market studies which assume an existing market experience for products and optimization approaches based upon static product performances, we propose an adaptable approach to designing a product or product family: the set-based design by usage coverage simulation. It starts with generating a usage scenario space for a set of representative users. Next, considering a candidate set of products, one proceeds to the CSP computations of feasible usage scenarios, assuming that physics-based models of performances are available. The comparison between the expected and feasible usage scenarios at the scale of a single user leads to Usage Coverage Indicators and finally to a preferred product which best covers the usage scenario space. At the level of a targeted consumer group, the approach provides a market share simulation for competing products or members of a scale-based product family. The design of a family of jigsaws thoroughly illustrates our approach.
\end{abstract}

Key-words: usage context based design, simulation under uncertainty, usage coverage metrics, Constraint Satisfaction Problem, set-based design.

\section{ANALYSIS OF THE TWO TRADITIONAL WAYS OF DESIGNING AN OFFER FOR A MARKET}

When one seeks to design an adapted product or product family for a market, two families of methods are available. The first method is technical driven focusing on design optimization of intrinsic performances and the second is market driven involving building a prediction model of the market share after conducting a tedious market study. Design optimization is now a well-known established research domain (see Papalambros 2002) with two primary families of approaches: 
- $\quad$ optimization of a unique objective function based upon a preference aggregation model (see Allen 2001 for example),

- $\quad$ multiple objective optimization (see for instance Messac et al. 1996) consisting of $n$ ultimate objectives in which the subset of optimal Pareto design solutions is computed (see for instance Messac et al. 2003) and a desired compromise on the Pareto surface is found automatically (Scott and Antonsson 2000) or interactively (Stump et al. 2004).

Conventional design optimization (see Figure 1) is generally a straightforward process, thanks to easy-to-build and easy-to-use preference models, widely available software solutions, and Pareto frontier representations. However, it is based upon strong hypotheses, namely that it is possible to express which functions and performances users are sensitive to and it is not required to know and represent the variability of customer demand. Expressing the objective(s) is based on a primary Functional Analysis (see Figure 1) which, for the convenience of design teams, averages the customers' needs into expected value functions and performance targets, and often does not discriminate between different usage or lifecycle situations. In addition, preference aggregation models typically incorporated in design optimization utilize time-averaged preferences obtained in contestable conditions; they may be built from surveys, by marketing experts, or by the design team itself. Figure 1 shows that, given this quite straightforward and approximate representation of market demand, design optimization mainly consists of finding the best design solution that maximizes an absolute user and time-average satisfaction or preference.

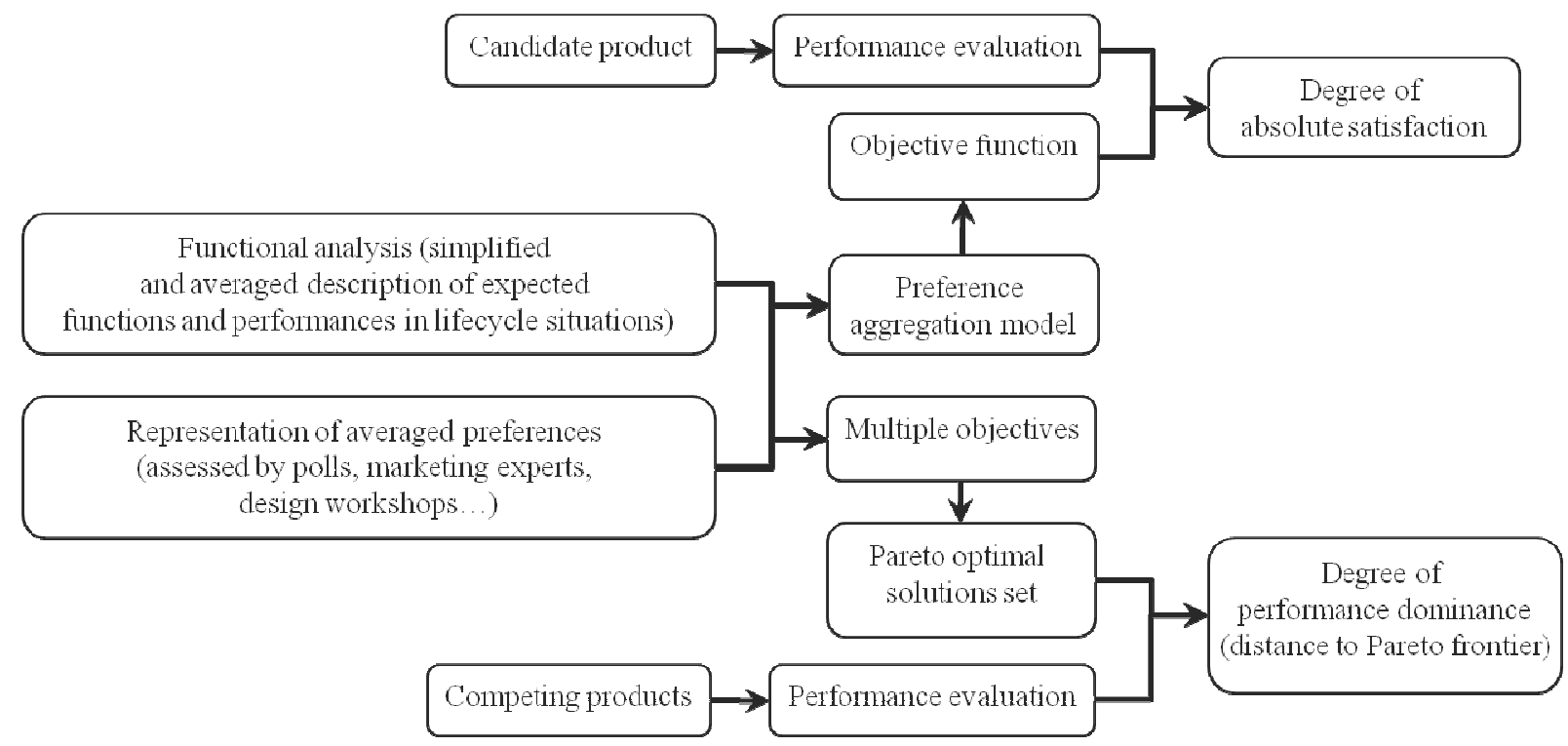

Figure 1. The design optimization framework

In short, engineers are motivated to obtain the best "average" performances for their product; these performances are considered independent of the user and usage context profiles, and the user preferences with respect to these performances are averaged. While this approach may be reasonable for certain products or populations, these extreme assumptions are deeply flawed if one wants to obtain a precise model of the adequacy of product features for a set of potential users addressing a variety of usage situations and expectations. Another argument with this approach is that this absolute performance is generally independent of existing competing products. In the best case, 
competing products may be represented in the Pareto frontier and the distance of a given design solution to the Pareto frontier may express a kind of competitiveness in the solution. However, neither this distance nor the aggregate preference (if computed) correctly models the effect of the price attribute and other service delivery attributes in a global utility ${ }^{1}$ or competitiveness model.

The second way of building a prediction model of market share is based upon user appraisals of the product utility. Consequently, this represents a market-driven approach to design (see Figure 2) which is quite difficult to conduct. It requires conducting a pre-segmentation of the market and, for each segment, the choice of a customer panel, the primary selection of attributes influencing their choice, the creation of a questionnaire, and finally the specification of a choice model and a market share model. Computing the utility of a product for a customer is a current practice for building a preference aggregation model, and many authors have compared Expected Utility Value Theory (EUVT) to other more declarative preference models, such as fuzzy models, to determine the best framework for design selection or design optimization, e.g. (Fernandez et al. 2001, Otto and Antonsson 1993a, Otto and Antonsson 1993b, Thurston 1991, Thurston and Liu 1991, Thurston and Carnahan 1992). However, assuming populationaveraged customer utilities may be as faulty an assumption as assuming an averaged preference over the user population. This is why marketing methods such as Conjoint Analysis (Green et al. 1981, Green and Srinivasan 1978) and Discrete Choice Analysis (Hoyle et al. 2010, Wassenaar and Chen 2003) have proposed to build choice models based upon EUVT, but starting with human appraisals of a customer panel to capture user heterogeneity. Kumar et al. (2007, 2009), for instance, directly tune a subset of relevant design parameters of a vehicle interior, considering user heterogeneity, to best compete in an existing SUV market. Nevertheless, these latter methods rely on tedious market investigations, gathering socio-demographic data of consumers as well as marketing attributes which describe both performances as well as technical attributes of the product alternatives. Consequently, these methods are not well adapted to radical innovations since, in these cases, consumers have no experience with the services provided by the new product, and hence with the technical attributes of the solutions.

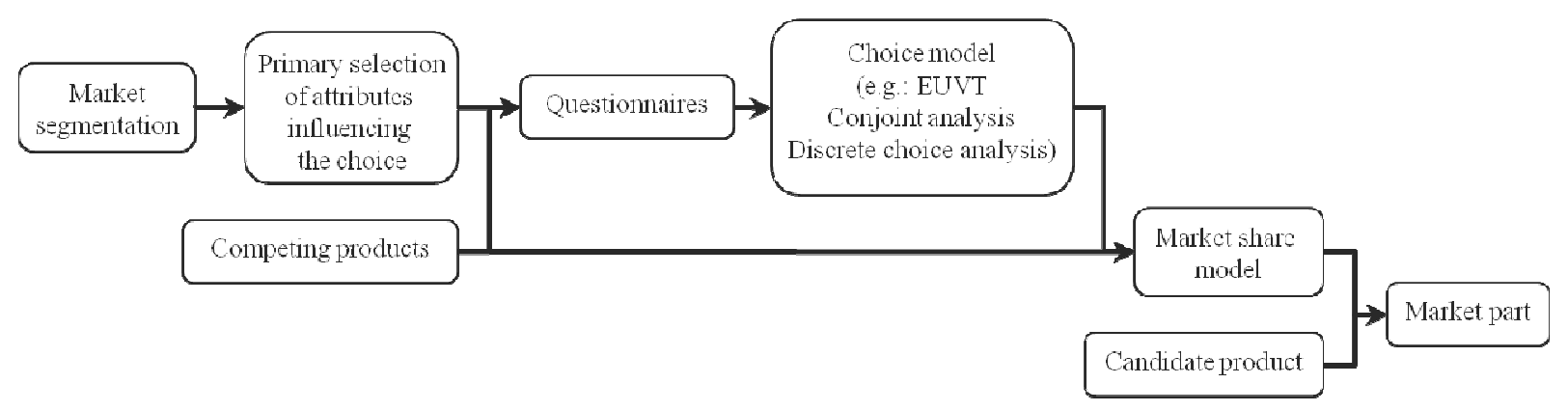

Figure 2. Choice and market share modeling framework

In summary, designing an appropriate product offer for a given market amounts to exploring the relationships between three spaces (see Figure 3) to make the best decisions:

- the space of product offer solutions, defined by the possible configurations and design parameter values,

\footnotetext{
${ }^{1}$ In the sense of the Expected Utility Value Theory (EUVT)
} 
- the space of product behavior defined by behavior performances in given usage, or lifecycle, situations,

- $\quad$ the market space defined by market segments, global satisfaction, and benefits.

The relationship between the behaviors and solution spaces may be modeled with performance models, i.e. using explicit physics-based formulations, or human appraisals for more subjective performances such as aesthetics or comfort. Another important consideration in this relationship is the skill of the users that interact with the nominal product performances which affect the quality of the service delivery. This aspect is also almost never considered when matching solutions to the market; however, finding an appropriate product for one's experience, skills and usage situations is a major concern for customers. Finally, the relationship between markets and behaviors is modeled using concepts of utility and preference.

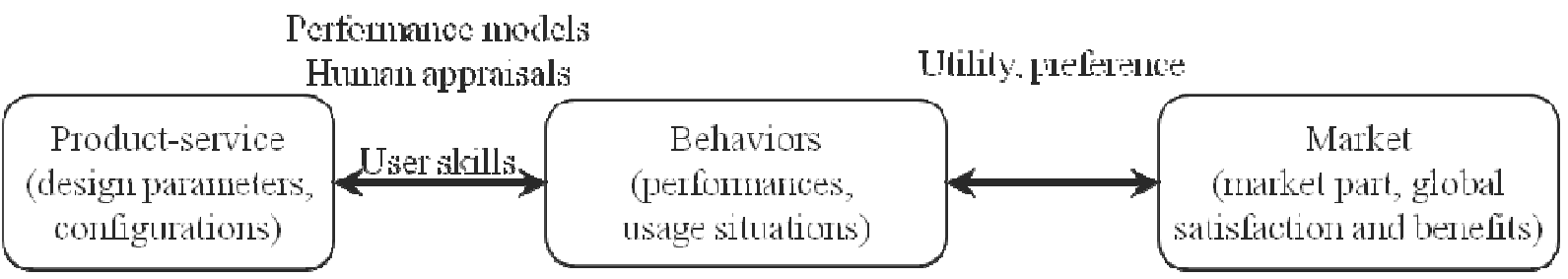

Figure 3. The three related spaces to explore to build an appropriate product offer to a given market

Improving methods for designing an adapted product, product or product family for a market, in more marketoriented, service-oriented and innovative situations requires addressing the four following questions:

- How to consider multiple usage/lifecycle situations?

- How to represent dissaggregate user/consumer expectations (i.e. do not average preferences)?

- How to model market expectations as completely as possible in situations of radical innovation given that:

- There is little market information on the offer benefits (it is unrealistic to build questionnaires on consumer experience)

- Consumers are more sensitive to fulfillment of their needs or usage scenarios than with solution attributes

- How to consider the effect of user skills on a product to estimate the final quality of the service delivered?

The remainder of this paper is a proposal of a third approach that we name "Set-based design by usage coverage simulation".

\section{PROPOSED APPROACH: A SET-BASED THINKING AND USAGE CENTERED APPROACH}

Our design framework is centered on two concepts: set-based thinking and an enhanced modeling of consumer expectations in terms of usage situations, as well as an enhanced representation of feasible usage situations for a given solution.

Set-based thinking, or set-based design, is a philosophy for conceiving concurrent engineering. Set-based design is one of the major principles of the Lean Product Development set of working principles that explains the design 
success of the Toyota company (see for instance Kennedy et al. 2008, Ward 2007, Ward et al. 1994). Basically, it consists of gathering, in advance, as much design information as possible in order to envision the consequences of a set of potential alternatives at any moment in the design process. In doing so, concurrent engineering is optimized because exploration of the possible solutions is enhanced, late-process design loopbacks are minimized, and impacts on dependent decisions are anticipated beforehand.

Set-based design has been studied at a high level as a managerial principle of concurrent engineering, but a number of attempts have also been made to implement it for technical solutions. Here, solution techniques known as Constraint Satisfaction Problem (CSP) techniques have proved to be closely aligned with set-based thinking (Bensana et al. 2000, Chenouard et al. 2007, Meyer and Yvars 2012, Vargas 1995, Yannou and Harmel 2005). CSP techniques are solution techniques for mathematical problems characterized by variables defined within a domain of potential values and mathematical constraints both linking and limiting the possible combinations of values for variables. The technique entails filtering as many infeasible values as possible from the domain and only considering the remaining alternatives at a given stage of the design process. In addition, designers are incented to continually shrink domain uncertainties to avoid design backloops. Finch (1999), Finch and Ward (1997) and Yannou and Hamel (2004) have demonstrated the utility of interval computation (one of the CSP techniques) in mechanical design for designing under uncertainty. CSP techniques have also been applied to other design applications, e.g., organization of multi-level design (Bliek 1995), conceptual design (Yannou and Harmel 2005), robust design (Qureshi et al. 2010) and collaborative design (Canbaz et al. 2011). When designing under uncertainty with CSP techniques, the final size of the shrunk solution space, or the relative shrinking versus the initial variable domain, reveals the relative degrees of freedom of the design (see Wood 2001, Yannou and Hamdi 2004), a measure we will further use when referring to usage coverage indicators.

Finally, our proposed method of "simulation by usage scenario coverage" is based on a database (or space) of representative usage scenarios (see Figure 4) that must be built either in a conventional manner using organized market questionnaires (see He et al. 2010, Wang and Yannou 2010 for such studies already led by the authors) or in a more declarative way by experts (see Wang 2012). The authors have also already studied in He et al. (2012) the literature of marketing research to derive some guidelines to elicit the relevant variables of the space of usage scenarios: combining description variables of usage contexts with attributes describing customer demographics and skills. In this previous publication (He et al. 2012), it is shown how the integration of usage-oriented variables in a discrete choice analysis process can advantageously improve the prediction of a market share. In the process of Figure 4, conditional upon formulating a physics-based model or human appraisal experiments for computing performances for a given usage situation, we showed in (Wang et al. 2012) how to use CSP techniques to reduce a space of needed usage scenarios (defined by domains) into a subset of the feasible usage space. Further (see Wang et al. 2012), usage coverage indicators (UCIs) have been proposed as a way to measure the potential to satisfy the entirety of specified usage scenarios, for a single user or for multiple users, and for a single product or a product family obtained by scaling design parameters (further called scale-based product family).

In summary, our approach does not specify technical attributes a priori when building the space of usage scenarios. Consequently, it is more likely to compute solution-independent market models which can serve as a decision aid in the case of innovative designs. In addition, a definitive advantage of our approach is that the performance models 
depend upon the customer profiles, notably the skill abilities and usage contexts, which are almost never considered in performance models in design engineering research, but which more closely the reflect real life situations.

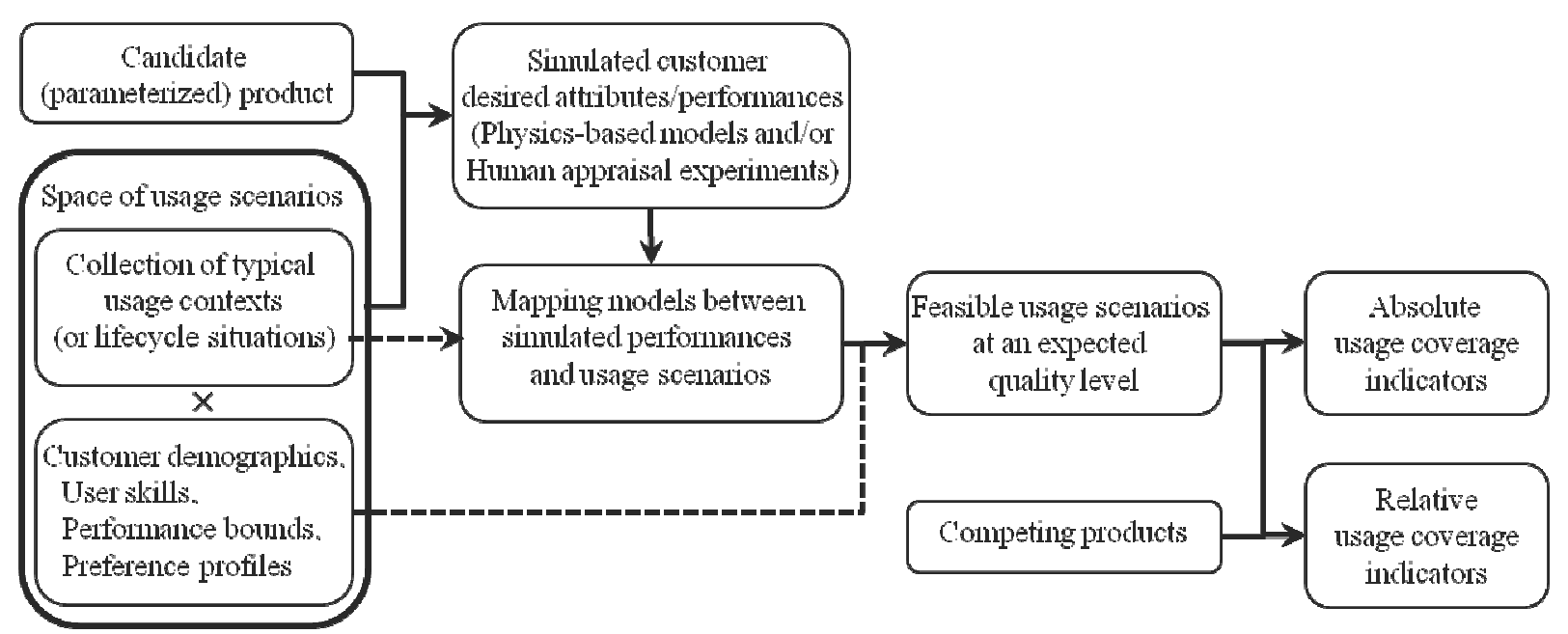

Figure 4. Set-based design by usage coverage simulation framework

We summarize the advantages and drawbacks of the three families of methods for designing an adapted product or product family for a market in Table 1.

This work is the first time we have assembled our works into a global proposal for set-based design by usage coverage simulation framework. The remainder of the paper consists of an enhanced literature review on marketing and engineering research about usage, and a summary of our results of usage coverage simulations for the design of a jigsaw, for a sole user and for multiple users, for a sole product or for a scale-based product family. 
Table 1 Comparison of the three families of methods to design an adapted product or product family for a market

\begin{tabular}{|c|c|c|}
\hline & Advantages & Drawbacks \\
\hline $\begin{array}{l}\text { Performance-based Design } \\
\text { Optimization }\end{array}$ & $\begin{array}{l}\text { No need to represent the variability of } \\
\text { customer demand. } \\
\text { Easy-to-build and easy-to-use } \\
\text { preference models, available software } \\
\text { solutions and Pareto frontier } \\
\text { representation. }\end{array}$ & $\begin{array}{l}\text { Often based on Functional Analysis which, } \\
\text { for convenience of design teams: } \\
\text { 1. averages the customers' needs into } \\
\text { expected-value functions and } \\
\text { performance targets } \\
\text { 2. often does not represent different } \\
\text { usage or lifecycle situations } \\
\text { Satisfaction of engineering performances } \\
\text { does not address user utility or choice } \\
\text { (what is the role of price?). } \\
\text { The performance models are not linked to } \\
\text { the customer profiles or usage contexts. }\end{array}$ \\
\hline $\begin{array}{l}\text { Utility/Choice or Market } \\
\text { Share model }\end{array}$ & Based on user appraisals. & $\begin{array}{l}\text { Required to conduct a significant customer } \\
\text { investigation (pre-segmentation, customer } \\
\text { panel, questionnaire, utility/choice/market } \\
\text { model). } \\
\text { Often based upon marketing attributes } \\
\text { which consist of performances and } \\
\text { technical solutions. } \\
\text { Not adaptable to radical innovations for } \\
\text { which consumers have no experience on } \\
\text { this product type. }\end{array}$ \\
\hline $\begin{array}{l}\text { Design by Usage Coverage } \\
\text { Simulation }\end{array}$ & $\begin{array}{l}\text { Does not specify a priori technical } \\
\text { attributes, enabling solution- } \\
\text { independent market models to be } \\
\text { estimated and to serve as a decision aid } \\
\text { in the case of innovative design. } \\
\text { The performance models depend upon } \\
\text { the customer profiles and the usage } \\
\text { contexts. } \\
\text { Starting from a representative set of } \\
\text { usage scenarios is easier than } \\
\text { administering a questionnaire for } \\
\text { targeted customers. }\end{array}$ & $\begin{array}{l}\text { Must start from a database of } \\
\text { representative usage scenarios. }\end{array}$ \\
\hline
\end{tabular}

\section{THE PLACE OF USAGE IN MARKETING AND ENGINEERING RESEARCH}

\subsection{Consumer goods are increasingly put in context with respect to use cases}

The marketing trend is undoubtedly to convince the consumer that they will be satisfied in their future consumption or usage of a product: firstly through appealing packaging, but also through more expressive labels on the shelves (see Table 2) and product demonstrations within the supermarket (e.g., activated toys, videos showing hand tools in usage). For example, new usage-oriented supermarket labels are being deployed by the second largest retailer in the world: Carrefour company. Table 2 shows that for a better alignment with client expectations with respect to coffee 
drinking, a common label for all coffee makers allows a clear usage comparison between different product types and brands. The main usage context variable is a combination of size and number of cups of a given quality. For the food mixer of Table 2, three usage contexts are described which combine a food process with a nutriment such as: chopping vegetables for a soup, whipping cream, or chopping different foods.

Table 2. New supermarket labels of CARREFOUR goods (published with the courtesy of CARREFOUR company) - The example of a coffee maker and a food mixer.

PRICE:

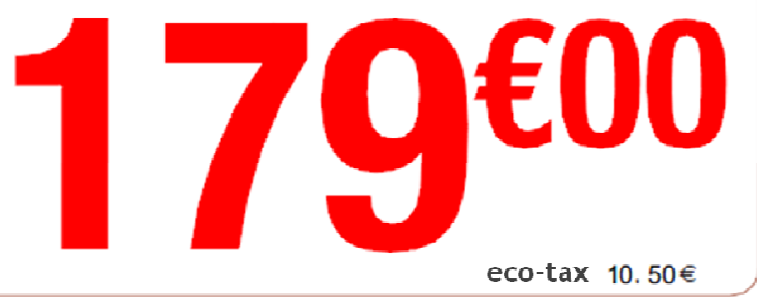

\section{Espresso with Capsules}

- Pressure: 19 Bar

- Power: $1260 \mathrm{~W}$

- Cup volume control: Yes

- Descaling indicator: No
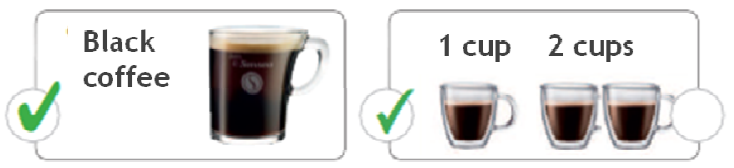

- capacity of the water tank: $1 \mathrm{~L}$

- Warranty: 2 years

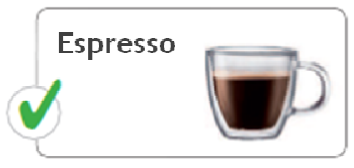

Fresh milk preparation

Included accessories:

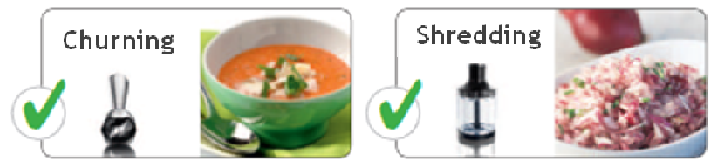

\section{Hand Blender}

\section{Moulinex DD405141}

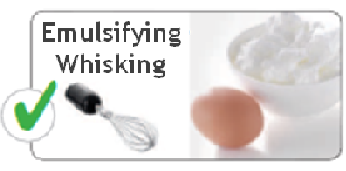

- Number of gears: 2

- Power: $600 \mathrm{~W}$

- Bowl capacity: 0.25 L

- Metal foot

- 4 accessories

- Warranty: 1 year

\section{PRICE:}

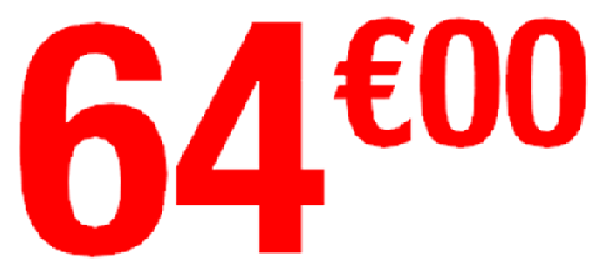




\subsection{Usage concept in marketing research}

Dickson (1982), three decades ago, advocated for a renewal of marketing research for better segmentation by considering usage situations: "A recent comprehensive state of the art review of market segmentation concluded that the field has become too fixed in its ways and that new conceptualizations of the segmentation problem should be explored. One convention that bears examination is the equating of market segmentation with customer segmentation. Markets can also be subdivided by usage situation. Although almost every conceivable person-based characteristic has been used to segment markets over the last decades, there has been a disturbing lack of consideration of the usage situation as a basis for defining product markets and modeling consumer choice behavior."

Despite the fact that the value of considering usage in marketing and engineering studies has been noted in the literature, little has been done to merge integrated approaches for resultant operational design methods.

It is well known in marketing research that consumer behavior is governed by so many factors that an exhaustive list is infeasible. Marketing researchers have proceeded to create a hierarchy and prioritization of these influencing factors upon consumer behavior, and the purchasing and repurchasing decision processes. Notions such as needs, feelings, reasoning process, motivations, information processes, perceptions, beliefs, memorization, and purchasing scenarios have been proposed and studied. The influence of psychological, socio-demographic, situational context, and market structure variables have been considered; as a result, a series of integrated models for consumer choice have been proposed. The Bettman model (1979, see Figure pp.17) is an information and cognitive processing theory of consumer choice as a series of screenings, interpretations, learnings and decisions. However, this is a generic schema, and there is no preconceived framework to define the factors considered by the consumers when making decisions. The model of Engel, Blackwell and Miniard (1978-1990, see Figure pp.481) relies upon the consumer memory to make a purchasing decision. This memory is built upon purchasing and post-purchasing experiences of products (e.g. usage, reliability, maintenance). This memory is used to retrieve relevant experiences when evaluating alternatives; to describe this process, the important dimensions are categorized as situational and environmental factors, personal and motivational factors, life style and socio-demographic factors. The most used and empirically validated model is the Howard and Sheth's (1969); it is also the first model to acknowledge the multiplicity of consumer decision processes which depend upon his/her own circumstances. One of these processes is a learning process consisting of appreciating service effectiveness, efficiency (quality), availability and price to build confidence about the product and trigger a purchasing intention. Holbrook and Hirschman's model (1982, see Figure pp.133) expands the traditional marketing considerations to leisure, cultural and social activities. The behavior may be studied from characteristic emotions and feelings of an experience, as opposed to primarily a consumption act. Recently, the importance of product usage by a consumer has been rediscovered as an essential element of the relationship between the consumer and the production company. In 1996, Philips (1996) recalled that usage anticipation is an essential part of the cognitive process of a consumer: the result of a mental simulation of a usage situation and of its consequences allows consumers to anticipate more precisely the consequences of a product use. The same idea that the consumer is a competent user prevails in Prahalad and Ramaswamy's paper (2000). 
Hoffmann, Roehrich, and Mathieu (2008, 2006) have stressed the role of usage anticipation and usage intention in the evaluation of a new product by an experienced consumer, and in the diffusion of an innovative product by the word-of-mouth effect. They consequently reassert the importance of usage anticipation as early as possible within the new product development process. In providing clear advantages to a product, experienced consumers may anticipate usage, develop a usage intention, and then create a purchase intention (see Figure 5).

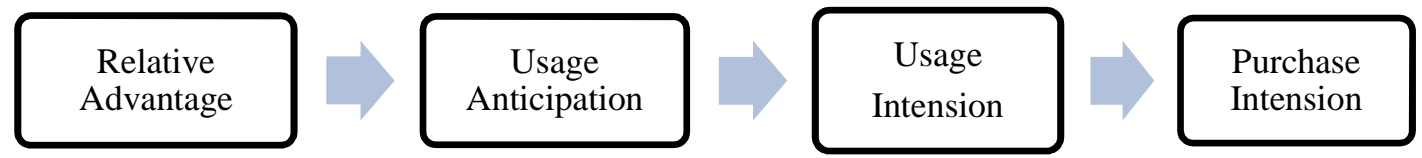

Figure 5. The Hoffmann, Roehrich and Mathieu $(2008,2006)$ model of usage anticipation and intention

\subsection{Computation of situational information}

Traditional information-processing research in consumer choice behavior has typically contented itself with stimulus and subject task manipulations. Deterministic preference/choice models are generally based on the premise that products are valued for the attributes they possess, and that customers seek to maximize their "utility" by choosing desired combinations of attributes (Green and Srinivasan 1978). Thus products offering similar combinations of levels of apparent attributes are likely to appear competitive and equally desirable, regardless of anticipated usages, user skills, experiences, goals, life styles and cultures. However, as previously noted, emerging streams of research seek to emphasize the role of usage context and goals in consumer learning and use of knowledge in decisionmaking. The emphasis upon matching situational requirements with product benefits has appeared in consumer behavior research since the 1980s (Srivastava 1981). Situational influences were seen as a moderating force in consumer choice behavior. This correspondence between situational factors and product attributes leads to the question: what are situational factors? Belk in his works $(1974,1975)$ proposed that environmental factors should include all variables not included in the description of persons or products - "all those factors particular to a time and place of observation which do not follow from a knowledge of personal (intra-individual) and stimulus (choice alternative) attributes and which have a demonstrable and systematic effect on current behavior", as illustrated in Figure 6.

\section{Situation}

$\begin{array}{ccc}\text { Object } & \text { Person } & \text { Behavior } \\ \text { STIMULUS } & \text { ORGANISM } & \text { RESPONSE }\end{array}$

Figure 6. A revised S-O-R paradigm (Belk 1975)

Belk also listed five groups of situational characteristics which represent the general features of the definition of situation with respect to a consumer's purchasing behavior:

1. Physical surroundings are the most readily apparent features of a situation, such as geographical and 
institutional location, decor, sounds, lighting, or other material surrounding the stimulus object.

2. Social surroundings provide additional depth to the description of a situation, such as other people present, their characteristics, their apparent roles and interpersonal interactions.

3. Temporal perspective is a dimension of a situation which may be specified in units ranging from time of day to season of the year, for example, time since last purchase, time since/until payday, etc.

4. Task definition features of a situation include the intent or requirement to select, shop for, or obtain information about a general or specific purchase.

5. Antecedent states are momentary moods (such as acute anxiety, pleasantness, hostility) or momentary conditions (such as cash on hand, fatigue) as opposed to the chronic individual traits.

Although this classification of situational factors is considered comprehensive in the marketing research, little related research in engineering design community appears. The situational aspect of a consumer's usage context is crucial however for product design or redesign evaluation.

Ratneshwar et al. (1993, 1991) suggested that usage context plays a key role in consumer problem-solving by impacting the discriminability among choice alternatives, and that the implicated processes might vary with situational familiarity. Contextual goals and constraints might help the consumer to discriminate acceptable alternatives from a much larger available set of alternatives. Even when the situation is relatively unfamiliar and the decision-maker has to take a more constructive approach to evaluating the alternatives, situational constraints might still facilitate discrimination, and rapid decisions, by focusing the consumer's attention on context-relevant product features. In general, the particular features that catch the decision-maker's attention are likely to be those that have relevance to the goal context of the ongoing situation (Huffman and Houston 1993). The role of usage context in consumer choice should then be to guide the search for and the evaluation of potential solutions. Finally, He et al. (2010) combined a usage context model and choice model for demand prediction applications.

\subsection{Usage in engineering research}

The research of usage situational/contextual information in design engineering has not been advanced significantly because of a lack of interdisciplinary marketing-engineering research. Consumer-participated interactive design (Bergman 2000), especially in IT products such as software, mobile phones, or navigation systems, began appearing a decade ago. In the domain of hi-tech product design, context-aware systems, i.e., systems with knowledge of the activity context and accounting for context in system behavior, are emerging. Context-aware systems for mobile cartography have been demonstrated in (Reichenbacher 2003), using formalization to describe situations and contexts to find typical context patterns.

The concept of usage context in design engineering has been first introduced in the works of Green et al. (2004, 2005, 2006) and Yannou et al. (2009). Green et al. have published three successive papers on the subject, with the goal of forming a comprehensive product design methodology that includes contextual factors. Important first steps in the field were taken, including the definition of key terms and concepts. Usage context, as it relates specifically to products, is defined as the unique combination of application and environment in which a product is used. 
Furthermore, usage context is framed as one part of a larger product design context, which also includes market and customer context. This illustrates the key role that all three contexts play in guiding the choice of the customer. During the course of the studies, customers were found to have distinct product preferences under different usage contexts. Luo (2011) also recently raised the importance of usage context in product family design, using a tolerance range in design parameters to represent the real product usage-context variance. Additionally, evidence supports that contexts could be differentiated based upon functional attributes, indicating a link between engineering parameters and perceived usefulness, which occurs under the influence of different usage contexts.

Finally, Yannou et al. (2009) presented a Usage Coverage Model (UCM) to provide a more thorough marketing model based on sets of permitted usages for a product, instead of the conventional perceived marketing attributes. In this work, a taxonomy of variables is suggested to create the link between the design parameters of a product and the subset of expected usages that may be covered. The concept of quantified individual performances during usage is proposed, offering the advantage of considering the user experience to estimate the perceived quality of a product's service. In the works (Wang et al. 2012, Yannou et al. 2010c), the UCM concept is applied to a power tool product, a jigsaw. The physics describing the behavior, usage context and consequently the performances of a jigsaw is established. When users choose to buy an adapted jigsaw, they may imagine different usage scenarios in which the product may be applied. A computed index reveals whether the product fulfills customers' requirements and expectations.

\section{INTRODUCTION OF USAGE COVERAGE OF CUTTING WOOD EXAMPLE}

In the following, we introduce our model of "set-based design by simulation of usage coverage" (Figure 4) through the example of the selection or design of a jigsaw tool or a scale-based family of jigsaws.

When a potential customer wants to buy a tool in a do-it-yourself (DIY) store for given wood cutting tasks, he or she faces a set of possible tool types (see Table 3) and, for each tool type, numerous brands and tool dimensions, possibly from a product family. One may imagine that he or she is perplexed or distressed because the sole information indicated on the label, such as electrical power, weight, size, price, and auxiliary functions such as variable speed motor, dust container or laser light, is typically not meaningful unless the client already has experience using such tools. 
Table 3. The main wood saw categories: which saw type to purchase?

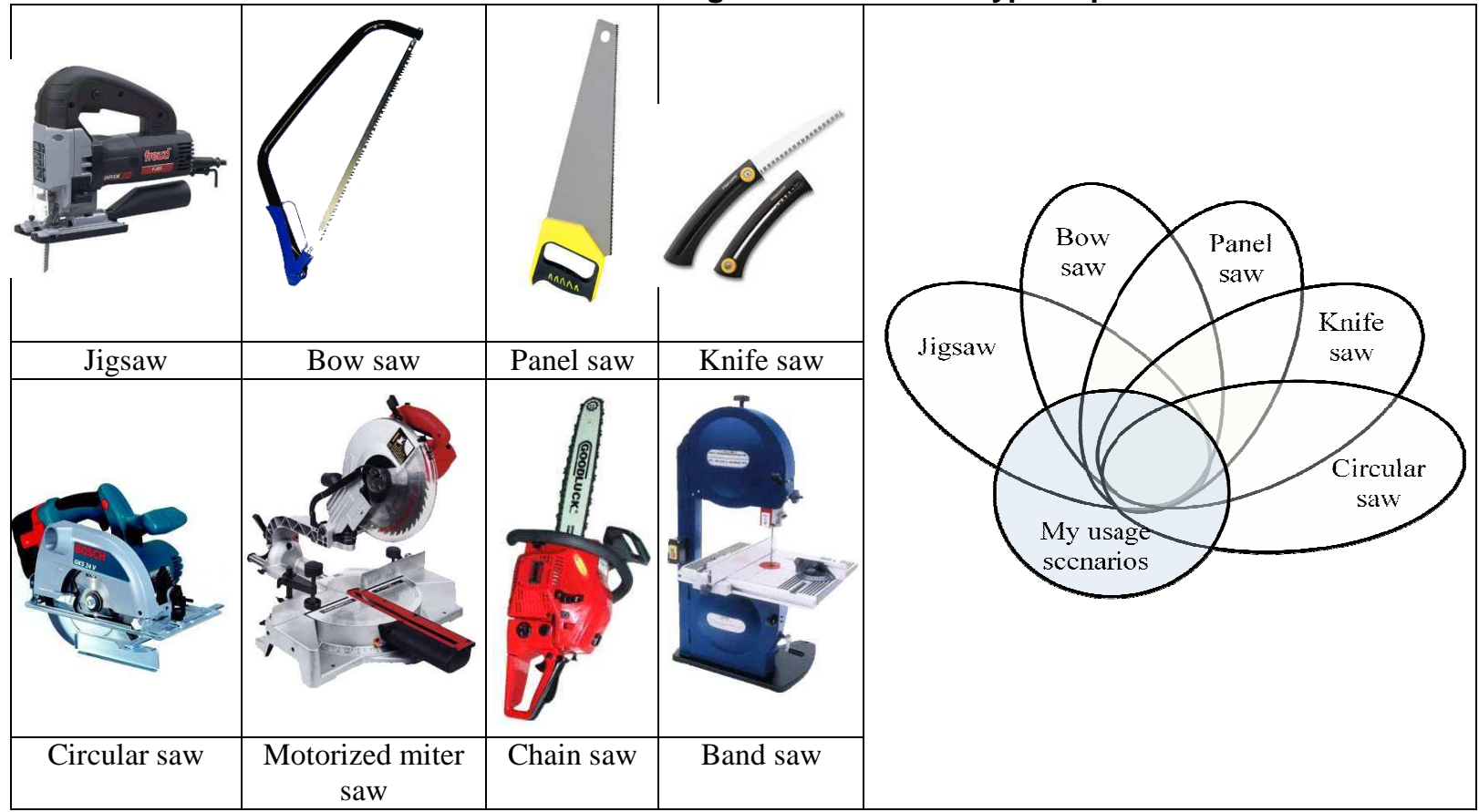

In such a situation, it can be seen that anticipating usage scenarios as described by Philips (1996) and Hoffmann, Roehrich and Mathieu (2006, 2008), in conjunction with other situational factors (e.g. one's skills, cash at disposal, set of saw tools already in possession), is a way to assess which tool is best adapted for the present situation. It is desired to simulate a consumer's thought process regarding how capable a product covers the entirety or a sufficient subset of the usage contexts he or she is able to anticipate (see right part of Table 3). In this work, we will differentiate between a usage context and a usage scenario. Assuming that building a space of usage scenarios is possible for an experienced user, i.e. a user who is able to anticipate his or her needs or usages, the subset covered by the feasible usage scenarios compared to the needed usage scenarios for a given product solution is quantitatively measured by a series of Usage Coverage Indicators (UCIs) we shall present hereafter.

In Table 4, we illustrate how the usage context attributes of "cutting wood tasks" can be defined by following the five basic categories of situational factors of Belk's classification (1974, 1975). It should be noted that based on Belk's classification, the scope of the usage context attributes is beyond the act of using the product, but also includes the context of purchase. 
Table 4. Five Categories of Usage Context

\begin{tabular}{ll}
\hline \hline \multicolumn{1}{c}{ Usage Context Type } & \multicolumn{1}{c}{ "Cutting wood tasks" example } \\
\hline \multirow{3}{*}{ Physical surroundings } & Location of cutting, \\
& Accessibility of an outlet, \\
& Availability of workbench, \\
& Distance to do-it-yourself (DIY) stores. \\
\hline Social surroundings & Presence of children, neighbors. \\
\hline \multirow{3}{*}{ Temporal perspective } & Expected process duration, \\
& Lifetime of similar cutting tools in possession, \\
& Estimated time needed to purchase the tools in a nearby DIY \\
& store. \\
& Material properties, \\
& Board thickness, \\
Task Definition & Minimal linear speed, \\
& Maximal vibration level, \\
& Noise and safety conditions, \\
& Accuracy requirements. \\
& Set of saw tools already in possession, \\
Antecedent states & New life conditions or projects, \\
& Cash at disposal. \\
\hline \hline
\end{tabular}

Physical surroundings are the most apparent characteristics of a usage. These characteristics include geographical location, weather condition, lighting, and other physical characteristics of a usage, as well as the distance to do-ityourself (DIY) stores when the new tool is needed. In the case of using a cutting tool for cutting a board, the location where the operation must take place (indoor/outdoor), the accessibility of a power outlet, the availability of a workbench are typical examples of physical surroundings.

Social surroundings provide additional information about the social situation of a usage. Whether another person is present, his/her influence on the user, and other social characteristics belong to this category. For instance, in cutting a board, one may prefer a jigsaw to a circular saw often used under these conditions for reasons of safety and noise due to the presence of children nearby.

Temporal perspective refers to those aspects of the purchasing situation or to those of a given usage which are specific for a given range of time. For instance, the expected process (cutting task) duration may be a reason for preferring a circular saw to a jigsaw, or a powerful jigsaw to a more basic one (faster linear speed). The age and expected lifetime of the cutting tools in possession are also deciding factors to determine how to upgrade the set of cutting tools in order to complete a set of cutting tasks. In terms of purchase situation, the time and emergency aspect for buying a new tool in a surrounding DIY store may also be a consideration under certain circumstances.

Task definition covers all features that explain the purpose of the purchase. For instance, one must consider the type of material to cut (wood, steel, etc.), the specification of the cut (blind or not, straight or wiggly, orthogonal or inclined), the properties of the material (cutting hardness which is physically proportional to the material density), the thickness of the board to cut (beyond a certain thickness, the cut is impossible), the minimal linear speed that is acceptable when the user delivers the maximal amount of arm forces and wrist torques, the maximal vibration level that is tolerable, or the admissible noise and minimal safety conditions. 
Antecedent states define a dimension of usage which is antecedent to the purchase. The factors for a new cutting tool acquisition may be the set of saw tools one already possesses (circular, chain, panel, bow, miter, etc.) and their respective age and expected remaining lifetimes, a new life condition or project (moving from an apartment to a house, or a house remodeling), and the cash at one's disposal.

\section{PARAMETERIZATION OF THE USAGE COVERAGE SIMULATION OF A JIGSAW}

The following list illustrates the principal notations used in this paper.

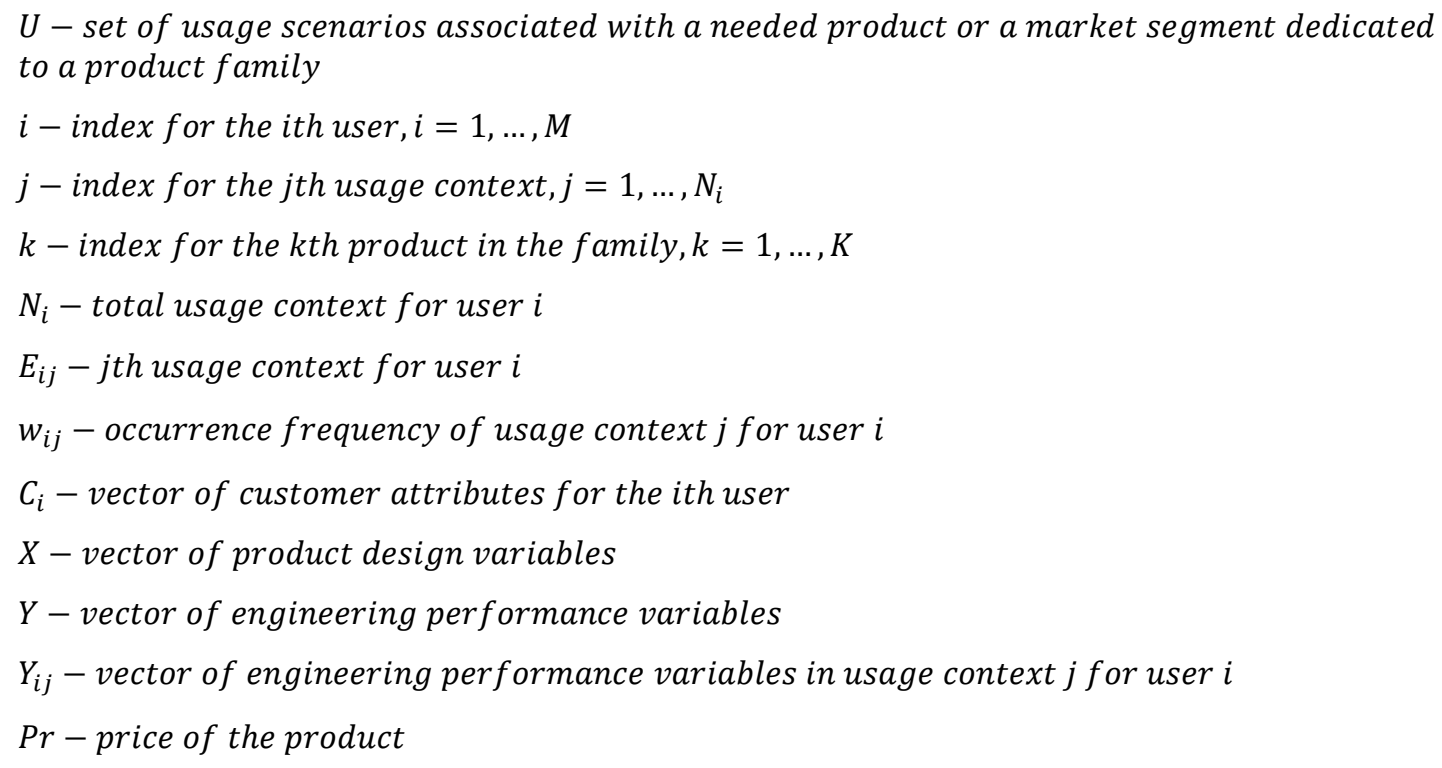

In our usage model, a product, defined by its design parameter vector $X$, must be adapted as much as possible to a set of customer usage scenarios $U$. "Usage needed" $U_{\text {needed }}$ is a set of expected, i.e. anticipated usage scenarios for a set of $M$ users (indexed over $i$ ) intending to use the product during its life. Each user $i$ is defined by a vector of customer attributes $C_{i}$. Each expected user, $i$, intends to use the product in a series of usage contexts $E_{i j}$, with each context being defined by a normalized usage occurrence frequency $\mathrm{w}_{\mathrm{i} j}$, representing the percentage of occurrences of a given usage context $E_{i j}$ in a year. Finally, the set of usage-needed of usage scenarios associated with a needed product or a market segment dedicated to a product family is defined in equation (1).

$U_{\text {needed }}=\left\{\left(\left(E_{i j}, w_{i j}\right), C_{i}\right)\right\}$ with $\forall j \in\left\{1, \ldots, N_{i}\right\}, \sum_{\mathrm{i}} w_{i j}=1$

This definition of $U_{\text {needed }}$ is set-oriented, since it represents a set of more and less frequent usage contexts; additionally, $E_{i j}$ is itself a vector of situational attributes defined over the domain of admissible values.

Given a product design $X$ and a user with certain expertise $\mathrm{C}_{i}$, it is reasonable to assume that the performances of the service are explicitly affected by the user and his/her experience with the product. So performance estimation formulas for each usage context are required, in the form of equation (2). 
$Y_{i j}=f\left(X, E_{i j}, C_{i}\right)$

When the performances meet certain basic criteria, such as being capable of meeting the given service requirement, we say that this usage is feasible for a given product by the user. In the case of a wood cutting tool, such as a jigsaw, this feasibility or minimum service delivery is the ability to effectively cut the wood. This can be done only if the tool is powerful enough and the user strong and experienced enough to make the cut. Thus, only a subset of this "usage needed" set may be fulfilled by a given product and user. This part is called "feasible usage"; only a subset of all the anticipated usage contexts $\mathrm{E}_{i j}^{*} \subseteq \mathrm{E}_{i j}$ may be done or "covered" for design $X$, as defined by equation (3). We will further see that this mathematical inclusion considers set inclusions, since $\mathrm{E}_{i j}$ is a set of usage context variables defined by value sets, either real intervals or discrete values.

$U_{\text {feasible }}\left(X, U_{\text {needed }},\left(C_{i}\right)\right)=\left\{\begin{array}{c}\left(\left(E_{i j}^{*}, w_{i j}\right), C_{i}\right), \text { such that } \\ \left(\left(E_{i j}^{*}, w_{i j}\right), C_{i}\right) \in U_{\text {needed }} \\ \text { and } E_{i j}^{*} \subseteq E_{i j} \\ \text { and } Y_{i j}=f\left(X, E_{i j}, C_{i}\right) \text { is feasible }\end{array}\right\}$

As an example, we have elicited a complete performance estimation model for a jigsaw, based on physics principles (kinematics, friction effects, wood cutting law, saw geometry). This performance estimation model is valid for any type of conventional jigsaw with horizontal handle, alternating saw and slider. A complete parameterization of the jigsaw problem may be found in paper of Wang et al. (2012) or in a technical document on internet (Yannou et al. 2010b). It has resulted in 46 equations, $12 X$ design variables, $2 Y$ performance variables, $2 E$ usage context variables, $2 C$ customer variables, and 19 intermediate variables which are mainly forces, speeds, wood densities $\rho_{w}$ and friction coefficients.

In practice, the usage context variables, given in equation (4), that influence the performance of wood cutting are the thickness of the wooden board or stick, and its wood type. It is noted that anticipating a usage context introduces both an epistemic uncertainty "Which thickness of wood board or stick, and which type of wood will I cut in the future?" as well as a stochastic uncertainty "Knowing that I cut a beam made of oak, what is the precise density of this oak?". This is why, in our equations set, there exists a correspondence table linking a wood type to an interval range of density measures of $\rho_{w}$, this density being the intrinsic material factor of the wood related to the cutting law: "the denser the wood, the harder to cut (and hence the slower the cut)".

$E=\left\{\begin{array}{c}T_{\mathrm{c}}-\text { Thickness of the wood board } \\ \text { Type }_{\text {wood }} \in\{\text { teak, oak, birch plywood ... }\}-\text { Type of wood }\end{array}\right.$

We consider two demographic variables $\mathrm{C}_{\mathrm{s}}=\{$ Gender, Skill $\}$ which are user-related parameters that affect performances.

$C_{s}=\{$ Gender - Gender of the saw user

$C_{s}=\{$ Skill - Skill of the user for cutting wood with a tool $\mathrm{X}$ 
These two variables define the maximal allowable bounds $F_{t \text { max }}$, the translation force, $F_{p \text { max }}$, the pressure force, and $\mathrm{M}_{\mathrm{w} \text { max }}$, the torque the user's wrist may deliver to the jigsaw. An assessment of these bounds with ergonomic analysis gives the correspondence table (Table 5).

Table 5. Correspondence table between gender and corresponding maximal force and torque admissible values

\begin{tabular}{ccccc}
\hline Gender & Skill & $F_{\text {t } \max }$ & $F_{p \max }$ & $M_{w \max }$ \\
\hline \multirow{3}{*}{ Female } & Basic user & $45 \mathrm{~N}$ & $90 \mathrm{~N}$ & $20 \mathrm{~N} . \mathrm{m}$ \\
\cline { 2 - 5 } & Medium & $80 \mathrm{~N}$ & $130 \mathrm{~N}$ & $40 \mathrm{~N} . \mathrm{m}$ \\
\cline { 2 - 5 } & Professional & $110 \mathrm{~N}$ & $170 \mathrm{~N}$ & $60 \mathrm{~N} . \mathrm{m}$ \\
\hline \multirow{3}{*}{ Male } & Basic user & $70 \mathrm{~N}$ & $105 \mathrm{~N}$ & $30 \mathrm{~N} . \mathrm{m}$ \\
\cline { 2 - 5 } & Medium & $100 \mathrm{~N}$ & $150 \mathrm{~N}$ & $50 \mathrm{~N} . \mathrm{m}$ \\
\cline { 2 - 5 } & Professional & $130 \mathrm{~N}$ & $195 \mathrm{~N}$ & $70 \mathrm{~N} . \mathrm{m}$ \\
\hline
\end{tabular}

We focus on the two essential performance criteria for the usage "to cut wooden boards" (see formula 6). The first one is the mean advance speed $S_{a}$. A non-null advance speed means that the tool is able to complete this service (feasible), which is expressed as Boolean Cut_ok $=\left(S_{a}>0\right)$ be 1 . The second one is the comfort during the cutting operation.

$Y=\left\{\begin{array}{c}S_{a}-\text { Mean advance speed of cutting } \\ P_{\text {comfort }}-\text { Degree of comfort in the user's wrist }\end{array}\right.$

The comfort of cutting with a jigsaw is mainly due to the wrist torque which must not exceed a maximal value the user can afford. It is expressed by equation (7).

$P_{\text {comfort }}=1-\left|\frac{M_{w}}{M_{w \max }}\right| \in[0,1]$

\section{SET-BASED DESIGN SIMULATIONS OF USAGE COVERAGE WITH CSP TECHNIQUES}

As already mentioned, solution techniques known as Constraint Satisfaction Problem (CSP) techniques have proved to be closely aligned with set-based thinking (Yannou and Harmel 2005). A Constraint Satisfaction Problem (Tsang $1993)$ is defined by a 3-tuple $(X, D, C)$ such that:

- $X=\left\{x_{1}, x_{2}, x_{3} \ldots, x_{n}\right\}$ is a finite set of variables that we call constraint variables, with $n$ the number of variables in the problem to be solved.

- $\quad D=\left\{d_{1}, d_{2}, d_{3} \ldots, d_{n}\right\}$ is a finite set of variable value domains of $X$ such that:

$$
\forall i \in\{1, \ldots, n\}, x_{i} \in d_{i}
$$

A domain can be a real interval or a set of discrete values such as integers or symbolic values, e.g. $\{$ teak, oak, birch plywood ... $\}$.

- $C=\left\{c_{1}, c_{2}, c_{3} \ldots, c_{p}\right\}$ is a finite set of constraints, with $p$ representing the number of constraints of the problem.

Solving a CSP amounts to instantiating each of the variables of $X$, and at the same time satisfying the set of problem constraints $C$ as indicated in equation (9).

$$
\forall i \in\{1, \ldots, p\}, \exists X_{i} \subseteq X / c_{i}\left(X_{i}\right)
$$


To achieve this, CSP solvers use a constraint propagation mechanism as a step-by-step interval (or domain) reduction process. Over the past few years, a variety of solution methods have been developed which enable fast computation of the CSP, and supply the user with intervals which are assured of containing all solutions of the CSP; this is the completeness property. A constraint can be any type of mathematical relation (linear, quadratic, non-linear, Boolean, etc.) covering the values of a set of variables. Functions operate on values but constraints operate on domains, shrinking them as much as possible. Information about propagation techniques and domain reductions can be found in (Benhamou and Granvilliers 2006, Collavizza et al. 1999, Davis 1987, Faltings 1994, Lebbah and Lhomme 2002, Moore 1966) for numerical CSP (with real variables) and in (Garrido et al. 2008, Macworth 1977, Montanari 1974) for discrete (mostly integer) CSP.

During the design process, designers use and manage design if/then rules, correspondence tables, abacus, etc. All these structures must be modeled as constraints (mathematical relations between variables linking domain values).

The CSP community has developed some work applicable to product and system design (Bensana et al. 2000, Chenouard et al. 2007, Vargas et al. 1994, Yannou and Harmel 2005, Yvars 2008). For example, dynamic CSPs enable one or more constraints to be added or removed. This allows configuration problems for the management of industrial product options to be processed as shown in (Aldanondo et al. 2003).

The jigsaw physics-based model has been modeled as a CSP using the ILOG Solver platform (see (IBM 2009)). The CSP technique is the best method to enable our design approach for several reasons:

1. It is desired to shrink the initial domain of the space of needed usage scenarios into the space of feasible usage scenarios. This is done by modeling the usage context attributes with constrained variables in the CSP platform. CSP techniques are therefore well suited for simulations of usage coverage (Wang et al. 2012, Yannou et al. 2010a, Yannou et al. 2010c).

2. The equation set for the jigsaw physics presents several causal loops of relations. This kind of circularity cannot be solved with spreadsheets such as MS Excel, unlike CSP solvers which manage these loops as sets of constraints.

3. We are in the presence of two types of epistemic uncertainties that must be correctly managed:

- The value of wood density is known with uncertainty. For instance, oak density is between 590 and 930 , teak density is between 630 and 720, birch plywood density is between 575 and 650 (see appropriate databases ${ }^{2}$ ), etc.

- With a jigsaw tool, a user may tune the stroke frequency $f$ between, approximately, 8.4 and $45.0 \mathrm{round} / \mathrm{s}$ for conventional jigsaws. Indeed, a variable speed motor may address a range of frequencies for a balance between the cut force $F_{c}$ and the advance speed $S_{a}$, given a fixed engine power $P_{m}$, to provide an effective cut for a given wood type of a thickness $T_{c}$ (at the condition that the power is sufficient). This possible variation of $f$ can directly be modeled as a value interval in our CSP system. Here, we assume in all our simulations that the user tunes his or her jigsaw for the best expected result, i.e. an effective wood cut at the highest advance speed.

2 The wood densities have been found on the two following web sites : http://www.gkehe.8m.com/data.htm, www.simetric.co.uk/si_wood.htm. 
According to the CSP model we must assign one domain of values to a constrained variable. Table 6 shows the initial intervals allocated, by default, to the different variables for any jigsaw problem.

Table 6. The default domain assignments for any jigsaw physics-based modeling

\begin{tabular}{|c|c|c|c|}
\hline Variables & Type & $\begin{array}{l}\text { Theore- } \\
\text { tical } \\
\text { domains }\end{array}$ & $\begin{array}{l}\text { First domain } \\
\text { assignments }\end{array}$ \\
\hline \multicolumn{4}{|c|}{ USAGE U (unique context E) } \\
\hline$T_{c}(m)$ & Continuous & ] $0,+\infty[$ & {$[0.001,0.01]$} \\
\hline $\begin{array}{l}\text { Type_wood } \\
\in\{\text { teak, oak ... }\end{array}$ & Discrete & \multicolumn{2}{|c|}{ see correspondence table } \\
\hline \multicolumn{4}{|c|}{ PERFORMANCES Y } \\
\hline$S_{a}(\mathrm{~m} / \mathrm{s})$ & Continuous & ] $0,+\infty[$ & {$[0.001,0.1]$} \\
\hline$P_{\text {comfort }}(\%)$ & Continuous & {$[0,1]$} & {$[0,1]$} \\
\hline \multicolumn{4}{|c|}{ DESIGN PARAMETERS X } \\
\hline$P_{m}(W)$ & \multirow{14}{*}{ Continuous } & \multirow{14}{*}{] $0,+\infty[$} & {$[50,3000]$} \\
\hline$m(k g)$ & & & {$[0.5,10]$} \\
\hline$f($ round $/ s)$ & & & {$[1,500]$} \\
\hline$A(m)$ & & & {$[0.01,0.1]$} \\
\hline$H(m)$ & & & {$[0.05,0.3]$} \\
\hline$L_{w}(m)$ & & & {$[0,0.2]$} \\
\hline$O_{S}(m)$ & & & {$[0,0.05]$} \\
\hline$L_{s}(m)$ & & & {$[0.1,0.15]$} \\
\hline$d(m)$ & & & {$[-0.15,0.05]$} \\
\hline$O_{t}(m)$ & & & {$[0,0.02]$} \\
\hline$L_{t}(m)$ & & & {$[0.01,0.1]$} \\
\hline$H_{t}(m)$ & & & {$[0.0001,0.01]$} \\
\hline$W_{t}(m)$ & & & {$[0.0002,0.003]$} \\
\hline$s(m)$ & & & {$[0.0005,0.005]$} \\
\hline$\alpha, \eta\left(^{\circ}\right)$ & Continuous & {$\left[0^{\circ}, 90^{\circ}\right]$} & {$\left[0^{\circ}, 90^{\circ}\right]$} \\
\hline$n$ (no unit) & Discrete & ] $1,+\infty[$ & {$[3,40]$} \\
\hline \multicolumn{4}{|c|}{ (Some) INTERMEDIATE VARIABLES } \\
\hline$\rho_{w}\left(\mathrm{~kg} / \mathrm{m}^{3}\right)$ & \multirow{2}{*}{ Continuous } & \multirow{2}{*}{] $0,+\infty[$} & {$[300,1000]$} \\
\hline$u_{s w}, \mu_{t w}($ no unit $)$ & & & {$[0.1,0.5]$} \\
\hline$F_{t}(N)$ & Continuous & {$\left[0, F_{t \max }\right]$} & {$\left[0, F_{t \max }\right]$} \\
\hline$F_{p}(N)$ & Continuous & {$\left[0, F_{p \max }\right]$} & {$\left[0, F_{p \max }\right]$} \\
\hline$H_{d}(m)$ & Continuous & ] $0,+\infty[$ & ] $0,0.005]$ \\
\hline$F_{t \max }(N)$ & \multirow{2}{*}{ Discrete } & \multirow{2}{*}{\multicolumn{2}{|c|}{ see correspondence table }} \\
\hline$F_{p \max }(N)$ & & & \\
\hline
\end{tabular}

\section{SIMULATION OF THE JIGSAW COVERAGE OF SOME USAGE SCENARIOS}

The first series of simulations we propose is for simulating the coverage of a set of usage scenarios for an existing jigsaw tool, namely the Bosch PST 50 AE jigsaw.

We assume a scenario in which a family determines which saw is best adapted to the usage needs of any of its members: two parents and three teenagers. They have a project to restore a wooden cottage together. They have 
variable skills with respect to the use of saws. Seven usage contexts for cutting wood have been formulated, depending on the assigned tasks to the family members (see Table 7). Here, usage contexts are defined by given values of (type_wood,thickness), such as (\{oak\},\{0.02\}). Usage contexts could have been assigned with our CSP-based language with sets of domains such as (\{oak, birch plywood $\},[0.015,0.035])$, but for simplicity here we preferred crisp values for both type of wood and thicknesses.

Table 7. Seven usage scenarios for cutting wood with different users

\begin{tabular}{|c|c|c|c|c|c|c|c|c|}
\hline \multirow{2}{*}{\multicolumn{2}{|c|}{ Usage scenarios space }} & \multirow{2}{*}{$\begin{array}{c}\text { Daughter } \\
\mathrm{a}\end{array}$} & \multirow{2}{*}{$\begin{array}{c}\text { Mother } \\
b\end{array}$} & \multirow{2}{*}{$\frac{\text { Father }}{\mathrm{c}}$} & \multicolumn{2}{|c|}{ Son \#1 } & \multicolumn{2}{|c|}{ Son \#2 } \\
\hline & & & & & d & $\mathrm{e}$ & $f$ & g \\
\hline \multirow[t]{2}{*}{$\begin{array}{l}\text { Usage } \\
\text { contexts } E_{i j}\end{array}$} & type_wood & oak & oak & $\begin{array}{c}\text { birch } \\
\text { plywood }\end{array}$ & $\begin{array}{c}\text { birch } \\
\text { plywood }\end{array}$ & fir & fir & fir \\
\hline & thickness & 0.025 & 0.025 & 0.03 & 0.05 & 0.04 & 0.04 & 0.035 \\
\hline \multirow{2}{*}{$\begin{array}{l}\text { User-related } \\
\text { variables } C_{i}\end{array}$} & gender & female & female & male & male & male & male & male \\
\hline & skill & basic user & medium & professional & medium & medium & basic user & basic user \\
\hline
\end{tabular}

Their task is to buy a saw that best fulfills the different needs, or "that best covers the usage scenarios needed". The Bosch PST 50 AE jigsaw is a candidate they envisage purchasing. The two performances (advance speed and wrist comfort) are considered as objectives, and no preference constraint is put upon them. Table 8 shows the design parameter values corresponding to the Bosch PST 50 AE jigsaw. These data are more constraining than those of Table 6. The sole non-crisp value domain is for a stroke frequency $f$, ranging from 8.4 and $45.0 \mathrm{round} / \mathrm{s}$. This possible variation of $f$ is directly modeled as a value interval in our CSP system.

Table 8. Design parameters $X$ for the Bosch PST 50 AE jigsaw

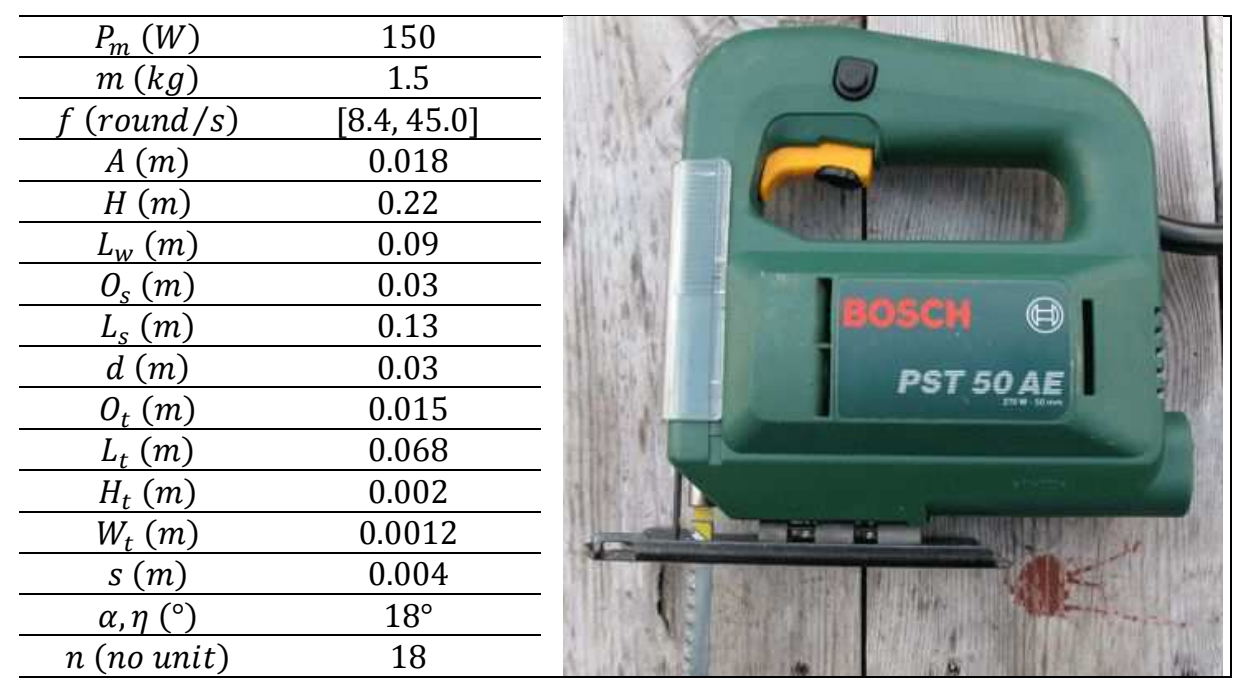

The simulation results in Table 9 show that with a Bosch PST50 AE jigsaw, we can cover the $\{b, c, e, g\}$ subset of the $\{a, b, c, d, e, f, g\}$ initial set of usages. The three usage scenarios $\{a, d, f\}$ are hard to fulfill for three different reasons: 
- For usage context $a$ : The task (thickness of 2.5 centimeters of oak, a notable hard wood) is too difficult for a basic female user.

- For usage context $d$ : The thickness is too large for a jigsaw tool using a common blade of standard length the case of using a longer blade is not considered here -.

- $\quad$ For usage context $f$ : The cutting operation is impossible for fir despite a low density of approximately 530, because the user is a basic user and a thickness of 4.0 centimeters is too large for such a user.

For the other feasible usage contexts $\{b, c, e, g\}$, the CSP computation provides the maximum allowable advance speed and the minimal comfort ratio. For instance, for usage contexts $\{b, c, e, g\}$, the advance speeds are $\{1.1,4.1,2.2,1.3\}$ millimeters per second, which are quite good advance speeds. The most tedious operations (advance speed around 1 millimeter per second) are for usage contexts $b$ and $g$, which correspond to nonexperienced people facing a wood piece of a typical thickness. Usage context $e$ corresponds to a mediumexperienced male, and the advance speed may reach 2.2 millimeters per second since it is directly related to the maximal forces $F_{t \text { max }}$ and $F_{p \text { max }}$ that the user may deliver.

The maximal advance speed of 4.1 millimeters per second is reached for usage context $c$ which corresponds to a male user with a professional skill cutting plywood, which is in general less dense than oak. It is not surprising to note that the maximal amount of comfort follows the same ordering as the advance speed. For usage contexts $\{b, c, e, g\}$, the maximal comfort ratios are $\{80 \%, 97 \%, 91 \%, 84 \%\}$. The professional male is more comfortable in usage context $c$ since his wrist is less taxed relative to the maximum allowable wrist torque.

Another interesting result from the CSP computation is the maximum allowable stroke frequency, which is limited to 12 rounds per second, far from the technical possibility of $45 \mathrm{rps}$. The reason is that, above this value of 12 rounds per second, the translation force $F_{t}$ applied to the wood section becomes insufficient to provide a positive height of wood shavings $H_{d}$. It denotes a non-trivial interaction of physics equations. This notion of minimal translation force $F_{t}$ is well illustrated by the existence of a non-zero lower bound of the $F_{t}$ variable. This phenomenon of a minimal translational force to start the advance will be experienced by users starting a cutting operation.

For this first experiment, the Bosch PST 50 AE jigsaw is able to cover 4 usage contexts out of 7 ; for these 4 usage contexts, the performance $S_{a}$ and $P_{\text {comfort }}$ are more or less satisfactory.

Table 9. 7 CSP results for the $\{a, b, c, d, e, f, g\}$ usage needed set. Bold values highlight extreme performances under each usage scenario (maximum speed advance, minimum comfort and maximum stroke frequency)

\begin{tabular}{|c|c|c|c|c|c|c|c|}
\hline & $\mathrm{a}$ & b & $\mathrm{c}$ & $\mathrm{d}$ & $\mathrm{e}$ & $\mathrm{f}$ & $\mathrm{g}$ \\
\hline Cut_ok & 0 & 1 & 1 & $\mathbf{0}$ & 1 & $\mathbf{0}$ & 1 \\
\hline$S_{a}(m / s)$ & & $\begin{array}{l}{[0.00100000,} \\
\mathbf{0 . 0 0 1 1 1 0 6 4}] \\
\end{array}$ & $\begin{array}{c}{[0.001,} \\
\mathbf{0 . 0 0 4 0 5 4 7 7}] \\
\end{array}$ & & $\begin{array}{l}{[0.00100000,} \\
\mathbf{0 . 0 0 2 2 1 0 0 3}]\end{array}$ & & $\begin{array}{l}{[0.00100000,} \\
\mathbf{0 . 0 0 1 3 3 1 8 9}]\end{array}$ \\
\hline$P_{\text {comfort }}$ & & $\begin{array}{c}\mathbf{0 . 7 7 9 3 2 1} \\
0.796168] \\
\end{array}$ & $\begin{array}{c}\mathbf{0 . 8 1 1 6 6 1} \\
0.966039] \\
\end{array}$ & & $\begin{array}{c}\mathbf{0 . 8 0 6 9 7 3} \\
0.908946] \\
\end{array}$ & & $\begin{array}{c}\mathbf{0 . 7 6 4 8 5 5} \\
0.835711] \\
\end{array}$ \\
\hline$f($ round $/ s)$ & & {$[8.4,12.31]$} & {$[8.4, \mathbf{1 0 . 4 7 7 8}]$} & & {$[8.4,9.36761]$} & & {$[8.4, \mathbf{1 0 . 7 5 3 5}]$} \\
\hline
\end{tabular}


In a second experiment, we change the design parameter of power of the Bosch PST 50 AE jigsaw, increasing from $150 \mathrm{~W}$ to $200 \mathrm{~W}$. The same CSP computations are performed, leading to the results of Table 10. In this experiment, the usage coverage is extended since usage contexts $\{\mathrm{a}, \mathrm{f}\}$ are now feasible.

Table 10. CSP results for the $\{a, b, c, d, e, f, g\}$ usage needed set for a jigsaw of $200 \mathrm{~W}$

\begin{tabular}{cccccccc} 
& \multicolumn{1}{c}{$\mathrm{a}$} & $\mathrm{b}$ & $\mathrm{c}$ & $\mathrm{d}$ & $\mathrm{e}$ & $\mathrm{f}$ & $\mathrm{g}$ \\
\hline & $\mathbf{1}$ & $\mathbf{1}$ & $\mathbf{1}$ & $\mathbf{0}$ & $\mathbf{1}$ & $\mathbf{1}$ & $\mathbf{1}$ \\
\hline$S_{a}(\mathrm{~m} / \mathrm{s})$ & {$[0.001$,} & {$[0.001$,} & {$[0.001$,} & & {$[0.00100000$,} & {$[0.00100000$,} & {$[0.00100000$,} \\
& $\mathbf{0 . 0 0 1 1 1 0 6 4}]$ & $0.00371680]$ & $0.00546453]$ & $0.00298814]$ & $0.00180478]$ & $0.00180478]$ \\
\hline$P_{\text {comfort }}$ & {$[0.955401$,} & {$[0.826927$,} & {$[0.815168$,} & {$[0.84026,1]$} & {$[0.886381$,} & {$[0.886381$,} \\
& $0.975332]$ & $1]$ & $1]$ & & $1]$ & $1]$ \\
\hline$f($ round $/ s)$ & {$[\mathbf{1 4 . 8 7 8 5}$,} & {$[8.40000$,} & {$[8.40000$,} & {$[8.40000$,} & {$[10.8791$,} & {$[10.8791$,} \\
& $\mathbf{1 6 . 5 2 4 6}]$ & $16.5246]$ & $14.0815]$ & $12.6013]$ & $12.6013]$ & $12.6013]$ \\
\hline
\end{tabular}

The usage scenario coverage appears to evolve from a value $4 / 7$ to $6 / 7$. But considering these coverages exclusively to make a decision on the motor power $(150 \mathrm{~W}$ or $200 \mathrm{~W})$ would be misleading. Indeed, variables defining the usage context may be defined by value domains and we must compare the relative sizes of the final, i.e., shrunk, feasible usage scenario domains and the needed usage scenario domains. However, there also exists an indirect usage-context variable, namely the wood density $\rho_{w}$, which is a constrained variable due to the stochastic uncertainty about the effective wood density of a given wood type which must be taken into account within the measure of usage coverage. Hence, we propose the following formula for the computation of the Usage Coverage Indicator of a single usage:

$$
U C I_{\text {single-usage }}=\text { feasibility } \times \frac{\prod_{i} \mid \text { usage_context_var }\left.\right|_{\text {feasible }} \times \prod_{j} \mid \text { indirect_context_var }\left.\right|_{\text {feasible }}}{\prod_{i} \mid \text { usage_context_var }\left.\right|_{\text {needed }} \times \prod_{j} \mid \text { indirect_context_var }\left.\right|_{\text {needed }}}
$$

with $\mid$ variable $_{x} \mid$ standing for the domain width $\boldsymbol{x}_{\max }-\boldsymbol{x}_{\min }$.

For the jigsaw use case, this results in the following:

$$
U C I_{\text {single-usage }}=C u t_{\text {ok }} \times \frac{\left|T_{c}\right|_{\text {feasible }} \times \mid \text { Type_wood }\left.\right|_{\text {feasible }} \times\left|\rho_{w}\right|_{\text {feasible }}}{\left|T_{c}\right|_{\text {needed }} \times \mid \text { Type_wood }\left.\right|_{\text {needed }} \times\left|\rho_{w}\right|_{\text {needed }}}
$$

For instance, for usage scenario $b$ of the Bosch PST50 AE jigsaw, one can compute from Table 9:

$$
U C I_{\text {single-usage b }}=1 \times \frac{0.025 \times \text { oak } \times|590-864.72|_{\text {feasible }}}{0.025 \times \text { oak } \times|590-930|_{\text {needed }}}=0.808
$$

Finally, an overall degree of coverage is computed through the formula:

$$
U C I_{\text {total }}=\sum_{j=1}^{N_{i}}\left(U C I_{i j k} \cdot w_{i j}\right) \text { for } N_{i} \text { usages }
$$

with $w_{i j}$ being the weights of usage contexts. They are assumed equal in this example.

Table 11 provides the degrees of coverage for the 7 usage scenarios. We can observe a significant improvement of the degree of usage coverage from $44 \%$ to $63 \%$ when increasing the motor power. But usage contexts $a$ and $f$ remain 
hard to fulfill for the reason of dense wood for usage context $a$ and large thickness and basic user for usage context $f$.

Table 11. Usage Coverage Indicators for the $\{a, b, c, d, e, f, g\}$ usage needed sets for the two jigsaw alternative designs at $150 \mathrm{~W}$ and $200 \mathrm{~W}$

\begin{tabular}{|c|c|c|c|c|c|c|c|c|}
\cline { 2 - 9 } \multicolumn{1}{c|}{$P$} & $\mathrm{a}$ & $\mathrm{b}$ & $\mathrm{c}$ & $\mathrm{d}$ & $\mathrm{e}$ & $\mathrm{f}$ & $\mathrm{g}$ & $\boldsymbol{U C I}_{\text {total }}$ \\
\hline $150 \mathrm{~W}$ & 0 & 0.808 & 1 & 0 & 0.432 & 0 & 0.849 & $\mathbf{0 . 4 4}$ \\
\hline $200 \mathrm{~W}$ & 0.086 & 1 & 1 & 0 & 1 & 0.347 & 1 & $\mathbf{0 . 6 3}$ \\
\hline
\end{tabular}

\section{SIMULATION OF USAGE COVERAGE FOR MULTIPLE USAGE SCENARIOS AND MULTIPLE CANDIDATE PRODUCTS}

\subsection{Parameterization of the usage coverage simulation for a product family}

We have generalized our principle of set-based simulation of usage coverage for multiple usage scenarios of multiple users and multiple candidate products (see also Wang 2012, Wang et al. 2012). As an example, we consider an existing scale-based jigsaw product family, such as 4 Bosch jigsaws (from P1 i.e. PST 650 to P4 i.e. Bosch PST900 in table 12), each with increasing power, weight and price. We study the adequacy of these 4 products for a targeted user segment, as well as the relative amount of scaling of the products in this family.

Table 12. The 4 products in Bosch jigsaw family

\begin{tabular}{ccccc} 
& P1 & P2 & P3 & P4 \\
\hline & PST 650 & PST 700 PE & PST 800 & PST 900 \\
Models & $1.5 \mathrm{~kg}$ & $1.8 \mathrm{~kg}$ & $2 \mathrm{~kg}$ & $2.2 \mathrm{~kg}$ \\
\hline Power $\left(P_{m}\right):$ & $120 \mathrm{~W}$ & $180 \mathrm{~W}$ & $200 \mathrm{~W}$ & $250 \mathrm{~W}$ \\
\hline Weight $(m):$ & $1.50 €$ & $80 €$ & $100 €$ & $130 €$ \\
\hline Price $\left(P_{r}\right):$ & $50 €$ & & \\
\hline \multicolumn{5}{c}{ Tunable stroke frequency $(f): 8.4-45 \mathrm{~s}^{-1}$} \\
\hline
\end{tabular}

We assume it is possible to build a representative needed-usage scenario space for the targeted user segment. For simplicity, we represent it as a table of $M$ users; each one has $N_{M}$ usage scenarios (see Table 13). The usages for each user are weighted with an occurrence frequency of usage context $w_{i j}$ conforming to equation (14).

$\sum_{j=1}^{N_{i}} w_{i j}=1$, with $i=1, \ldots, M$

We will also consider, for simplicity of the example only, that the usage contexts are defined with crisp values and not value domains. Finally, these $M$ users face the $K$ products of the scale-based family which perform the same service of cutting wood with varying degrees of success. Set-based design simulations of usage coverage are conducted with adequate metrics to assess the product family regarding the targeted user segment. 
Table 13. Needed usage scenario space for the targeted user segment

\begin{tabular}{|c|c|c|c|c|}
\hline User Id & Usage $_{i, 1}$ & Usage $_{i, 2}$ & $\ldots$ & Usage $_{i, N i}$ \\
\hline User 1 & $\mathrm{E}_{11}\left(\mathrm{w}_{11}\right)$ & $\mathrm{E}_{12}\left(\mathrm{w}_{12}\right)$ & $\ldots$ & $\mathrm{E}_{1 \mathrm{~N} 1}\left(\mathrm{w}_{1 \mathrm{~N} 1}\right)$ \\
\hline User 2 & $\mathrm{E}_{21}\left(\mathrm{w}_{21}\right)$ & $\mathrm{E}_{22}\left(\mathrm{w}_{22}\right)$ & $\ldots$ & $\mathrm{E}_{2 \mathrm{~N} 2}\left(\mathrm{w}_{2 \mathrm{~N} 2}\right)$ \\
\hline User 3 & $\mathrm{E}_{31}\left(\mathrm{w}_{31}\right)$ & $E_{32}\left(w_{32}\right)$ & $\ldots$ & $\mathrm{E}_{3 \mathrm{~N} 3}\left(\mathrm{w}_{3 \mathrm{~N} 3}\right)$ \\
\hline \multicolumn{5}{|l|}{$\ldots$} \\
\hline User M & $\mathrm{E}_{\mathrm{M} 1}\left(\mathrm{w}_{\mathrm{M} 1}\right)$ & $\mathrm{E}_{\mathrm{M} 2}\left(\mathrm{w}_{\mathrm{M} 2}\right)$ & $\ldots$ & $\mathrm{E}_{\mathrm{MNM}}\left(\mathrm{w}_{\mathrm{MNM}}\right)$ \\
\hline
\end{tabular}

For example, if a Female Basic User (see Table 5) wants to cut a hard wooden board (such as oak) of $0.035 \mathrm{~m}$ thickness, a medium wooden board (such as pine) of $0.050 \mathrm{~m}$ thickness, and a soft wooden board (such as birch plywood) of $0.015 \mathrm{~m}$ thickness, each usage scenario will be given relative weighted importance, i.e. usage occurrence frequencies $w_{1}, w_{2}, w_{3}$. She has 4 Bosch jigsaws listed in table 12 to choose from in a purchasing situation. Here, we consider that there is no external competition. We can rationally expect that she will choose the product that covers the most usage scenarios, with good performance for each, and an affordable price. Therefore, we introduce some simple metrics to describe this reasoning process.

If preference data were available, we could derive the utility functions for each user, which is in direct contradiction with the minimal preference data assumption of our method. For this reason, we have formulated a typical generic form of a utility function, in the form of a ratio of user experienced quality (i.e. performance) versus price. This form follows the general recommendations of Train (2003) and Koppelman et al. (2006) to utilize interactions (i.e. ratios) of user-varying versus product-varying attributes in the utility specification.

For each Product $P_{k}$ and user $i$, a series of $N_{i}$ Usage Coverage Indicators (UCIs) are calculated (see formulas (10) and (11)). For a current $j$ usage scenario, a normalized user's decision index CI is calculated following formula (15). The higher the usage coverage and the performance for a given user/usage-scenario/product and the lower the product price, then the higher this new user's decision index CI. This index appears as a value indicator in a value engineering approach.

$C I_{i j k}=\frac{\left|U C I_{i j k}\right| \times \mid \text { Performance }_{i j k} \mid}{\mid \text { Price }_{k} \mid}$

Then, an aggregated total value for each pair (user k, product $P_{k}$ ) is calculated using formula (16).

$C I_{i k}=\sum_{j=1}^{N_{i}}\left(C I_{i j k} w_{i j}\right)$, with $i=1, \ldots, M$

User $i$ must logically choose the product $P_{k}$ with the highest value, following formula (17).

Choice $\left(\operatorname{User}_{i}\right)=\max _{P_{k}}\left(C I_{i k}\right)$, with $k=1, \ldots, K$

A rational usage market share for the products of the family can then be established by summing the number of times each product is chosen by users. This market share would be the actual market share if users behaved in a rational manner with respect to their anticipated usage contexts. 
Finally, for the case of the jigsaw family, the choice for a given user is provided by formula (18).

$\operatorname{Choice}\left(\operatorname{User}_{i}\right)=\max _{P_{k}}\left(\frac{\sum_{j=1}^{N_{i}}\left(\left|U C_{i j k}\right| \times\left|S_{a i j k}\right| \times\left|P_{\text {comfort } i j k}\right| \times w_{i j}\right)}{\mid \text { Price }_{k} \mid}\right)$, with $k=1,2,3,4$

An alternative approach to formula (17) is to utilize a Multinomial Logit (MNL) choice model to estimate choices and, hence, market share (Ben-Akiva and Lerman 1985, McFadden 1974). It is assumed that market data is not available for maximum likelihood model estimation, and therefore a method of model coefficient calibration, as opposed to model estimation, is utilized. In model coefficient calibration, MNL model coefficients appearing in an observed utility function, $W_{i k}$, are derived from econometric considerations, such as estimated price elasticity and relative worth (in units of currency) of product attributes (Greene 2001, Santini and Vyas 2005). In this work, the observed utility function, $W_{i k}$, can be assumed to be of the form given by $C I_{i k}$ in formulas (15) and (16), or can be of a form in which price and performance are additive (e.g., a linear utility model). In the MNL approach, choice probabilities are computed using formula (19):

Choice $_{j}\left(\right.$ User $\left._{i}\right)=\frac{e^{W_{i j}}}{\sum_{k=1}^{K} e^{W_{i k}}}$, with $k=1, \ldots, K$

\subsection{Results of simulations}

For experimental illustration, we randomly generate a panel of 100 users from 6 different types, using a combination of gender and skill in $\mathrm{C}_{i}$ variables. Each of the users has at most 6 usages with differing weights. The usages are also generated with 3 types of wood (soft, medium, hard) and with a thickness that is uniformly distributed in the interval $[0.010,0.060] \mathrm{m}$. Needed usage scenarios such as those of Table 13 are generated randomly. The user's decision to choose an appropriate jigsaw for corresponding at best at his or her anticipated set of usages is based on the user decision index CI described by formulas (15) to (18).

The existing Bosch Jigsaw product family, whose features are listed in Table 12, is used as a reference in Table 14 and denoted as $100 \%$ of power, weight, and price (i.e. the baseline performance). We can see that, for a uniformdistributed usage scenario case, the baseline jigsaw product family corresponds well with the target usage market: P1 achieves 30\% market share, P2 41\%, P3 6\%, and P4 17\%, with only 6\% of users unable to find an appropriate jigsaw for their specific usage scenarios. Products P1, P2, and P4 account for $88 \%$ of the market share, while P3 is redundant since $\mathrm{P} 4$ can also absorb these $6 \%$ while lowering the number of product references. 
Table 14. Products' usage market share estimation

\begin{tabular}{|c|c|c|c|c|}
\hline & Power, Weight, Price & $50 \%$ & $100 \%$ & $150 \%$ \\
\hline \multirow[t]{3}{*}{ P1 } & Average Decision Index $(C I)$ & 0.022 & 0.141 & 0.164 \\
\hline & Average Usage Coverage Indicator $(U C I)$ & 0.035 & 0.300 & 0.522 \\
\hline & User Choice & 3 & 30 & 61 \\
\hline \multirow[t]{3}{*}{$\mathrm{P} 2$} & Average Decision Index $(C I)$ & 0.099 & 0.156 & 0.158 \\
\hline & Average Usage Coverage Indicator $(U C I)$ & 0.166 & 0.522 & 0.698 \\
\hline & User Choice & 24 & 41 & 32 \\
\hline \multirow[t]{3}{*}{ P3 } & Average Decision Index $(C I)$ & 0.101 & 0.141 & 0.138 \\
\hline & Average Usage Coverage Indicator $(U C I)$ & 0.211 & 0.574 & 0.732 \\
\hline & User Choice & 3 & 6 & $\mathbf{0}$ \\
\hline \multirow[t]{3}{*}{$\mathrm{P} 4$} & Average Decision Index $(C I)$ & 0.117 & 0.137 & 0.123 \\
\hline & Average Usage Coverage Indicator $(U C I)$ & 0.321 & 0.671 & 0.755 \\
\hline & User Choice & 54 & 17 & 4 \\
\hline $\mathrm{X}$ & Users do not choose & 16 & 6 & 3 \\
\hline
\end{tabular}

For illustrative purposes, we generate two other fictive product families, scaled down or up respectively by $50 \%$ and $150 \%$ of the power, weight and price of the given Bosch Jigsaw product family. They can be considered as competing or alternative jigsaw product family compositions. The former consists of less powerful and less expensive products. The latter is, conversely, more powerful and more expensive. For the given target usage market, represented by the user panel, the question is whether the Bosch Jigsaw family composition is well composed or not. For a less powerful product family (scaled down by 50\%), the percentage of users whose usage scenarios have no feasible choice in the family increases from $6 \%$ to $16 \%$. The given panel of users shifts to the more powerful products P2, P4 as shown in Figure 7. For the case of the more powerful product family (scaled up to 150\%), firstly, the increase in no-choice users is less significant; secondly, the more powerful products P3 and P4 are less preferred due to their higher price. 


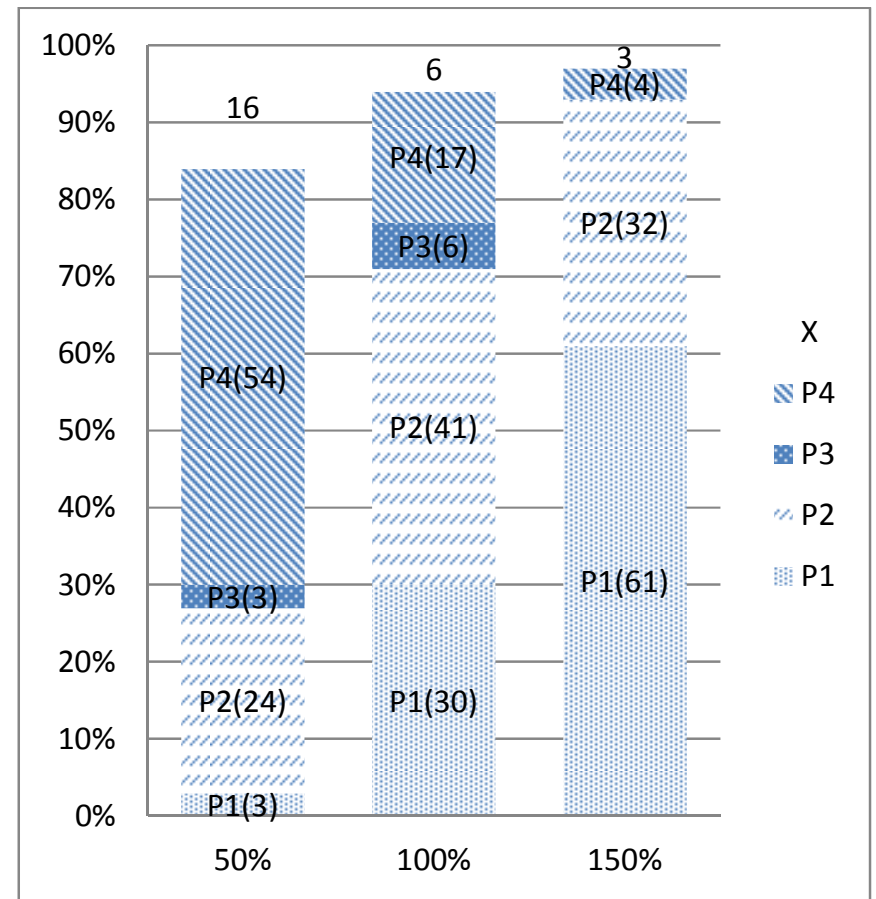

Figure 7. The usage market shares for the jigsaw families

The above comparison reveals that the baseline Bosch Jigsaw family studied covers the target usage market quite well. However, since the product P3 is too close to P2 and P4's performances (similar specification) and P2 has better usage coverage and performances for its price while $\mathrm{P} 4$ is more suitable for extremely hard usages, product $\mathrm{P} 2$ and P4 cannibalize the market share of P3. A better composition of products in the family can be further studied in regard to the target usage market.

For studying the influence of the user market segmentation, we take two extreme cases: a male professional user and a female basic user; each user type will face easy wood board cutting usage scenarios (wood type 0 or 1, thickness drawn uniformly from $[0.01,0.03]$ ) and hard wood board cutting usage scenarios (wood type 1 or 2, thickness drawn uniformly from $[0.03,0.06])$. The choice of products of a randomly generated group of 100 typical users with a set of usage scenarios is shown in Figure 8. 


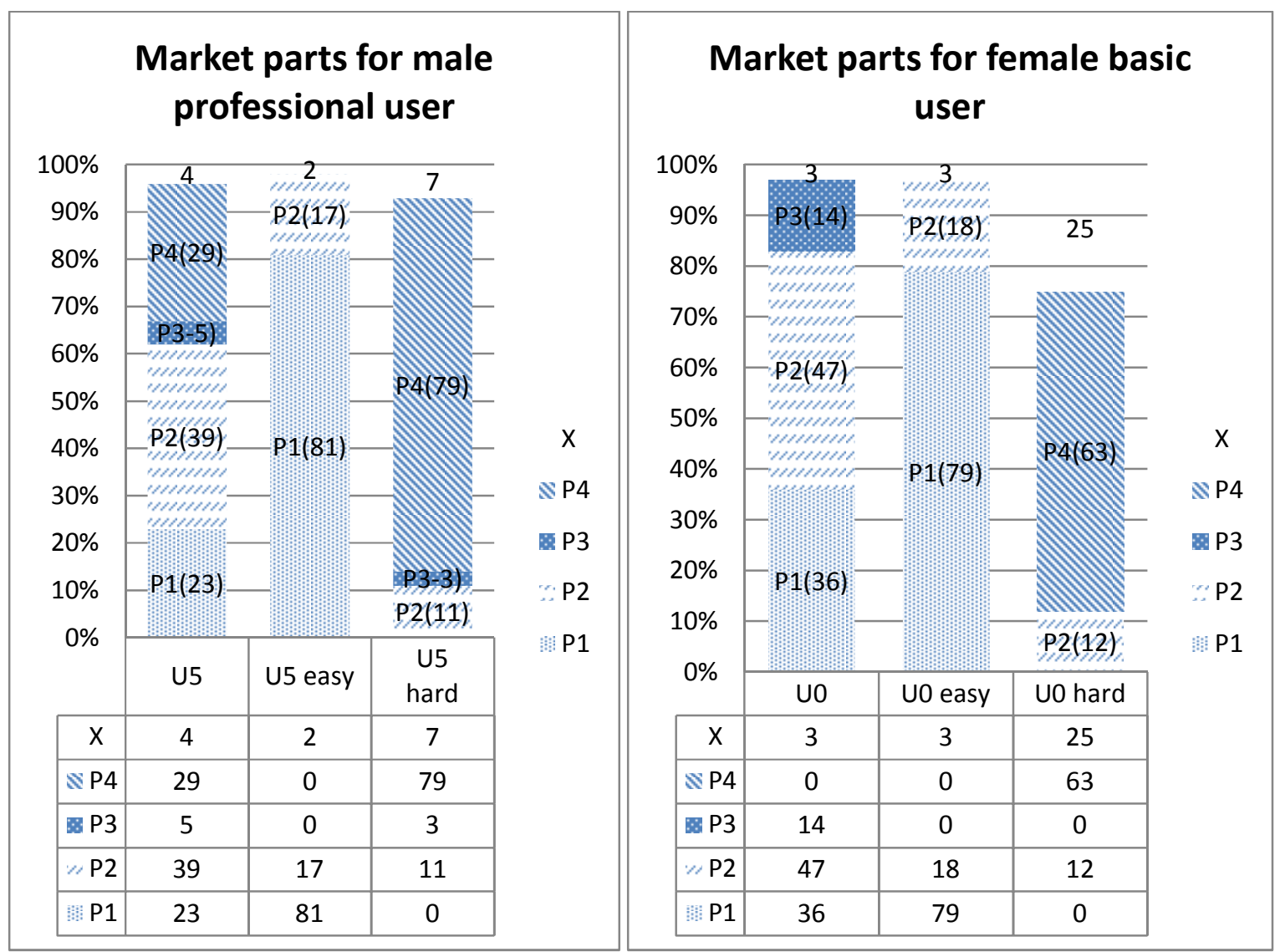

Figure 8. The market parts for the products in Bosch product family for professional/beginner user

In the left-hand chart, we can see that for male professional users cutting wood boards, P4 is preferred for their difficult usage scenarios, while P1 or P2 are preferred for the easy usage scenarios. This justifies the existence of product P4. A professional user with all the range of usage scenarios (column 1) may choose any of the three products P1, P2, or P4. For the female basic users in the right-hand chart, products P1and P2 are the most preferred. P3 can be substituted by either P2 or P4 while $25 \%$ of the difficult usage scenarios cannot be served by any product in the family.

\section{CONCLUSION}

This paper has first presented an extensive literature review on marketing and engineering research about usage, and particularly how to take into account usage intentions and anticipations for the design of products or product families. We have described the two conventional design approaches: the performance-driven engineering design optimization framework (see Figure 1) and the marketing choice and market share modeling framework (see Figure 2). We conclude that they suffer from a lack of realism in terms of simulation of personal usage needs. Optimization is mostly based on averaged expected performances independent of specific users' skills, sets of anticipated usage scenarios, and competing products on the market. Additionally, marketing choice and market share models require tedious market investigations assuming an existing market experience of products, which is not the case for 
disruptive products. This is why a usage-centered model-based approach, as proposed in Figure 4, has value in the design process. We name this approach the set-based design by usage coverage simulation.

Set-based design by usage coverage simulation consists of applying set-based thinking principles derived from Constraint Satisfaction Problem (CSP) techniques. First, one generates a usage scenario space for a set of representative users. Our approach does not a priori assume technical attributes when building the space of usage scenarios. Consequently, it is then more likely to compute solution-independent market models and to serve as a decision aid in case of innovative designs. Next, considering a set of candidate products, possibly of a scale-based product family, one proceeds to make CSP computations of feasible usage scenarios (in a set-based design spirit), provided that physics-based modeling of performances is possible. The comparison between the expected and feasible usage scenarios at the scale of a single user, considering the level of delivered performances and product price, leads to Usage Coverage Indicators (UCIs) and finally to a preferred product best covering the personal usage scenario space. UCIs have been proposed as a way to measure the potential to satisfy the entirety of anticipated usage scenarios, for a sole user or for multiple users, for a sole product or for a scale-based product family. A definitive advantage of our approach is that the personal usage coverage simulation of a customer/user depends upon his/her profile, notably skill abilities and usage contexts. User profile is almost never considered in performance models in design engineering research but which can dramatically influence performance in real life situations. The objective is to simulate how people evaluate if a given product is capable of covering the entirety or a sufficient subset of the usage contexts he or she is able to anticipate.

At the level of a targeted consumer group, the approach leads to a market share simulation of competing products or members of a scale-based product family. Our model-based approach has been thoroughly illustrated by the usage coverage simulations for the design of a jigsaw, for a sole user and for multiple users, for a sole product and for a scale-based product family. If we had used traditional design optimization, we may have created a design satisfying a fictitious "averaged" user but not actual users, i.e., a design optimized with respect to average user needs by treating consumers as a group without considering the differences in usage context. As expected, based on the difference in the principles of these two problem formulations, the results of averaging consumer needs will be unsatisfactory to meet real heterogeneous user needs. If we had used the utility market share model approach, we would have required construction of a discrete choice model requiring extensive surveys and a choice data set, which is currently unavailable for the jigsaw problem. Based on these two arguments, the utility of the proposed method is demonstrated, given the following conditions:

- $\quad$ The physics-based models of performances are available,

- Uncertainties can be represented by intervals or sets of values,

- $\quad$ Consumer and product behaviors can be modeled with a set of equations, and constraints can be expressed in terms of the continuous and discrete variables appearing in these models.

- We are able to build the usage scenario space in a robust and representative manner.

In cases where these conditions apply, the set based design approach creates a mathematical link between the product and the user, allowing designers to efficiently explore the feasible design space and specifically target the real needs of the consumers either with a single product or a family of products. 
In terms of future work, we are currently developing mapping operators between product service system design concepts and the usage scenario space, to replace physics-based models of performances when not available. For example, one such Product-Services-System is a method to prevent, avoid, or diminish the effects of falls of the elderly.

\section{REFERENCES}

Aldanondo M., Hadj-Hamou K., Lamothe J., 2003. Product generic modelling for configuration : Requirement analysis and modelling elements (Chapter 3), In Intelligent agent-based operations management (ISBN 1-9039-9643$0)$, eds Kogan Page, London, 50-70.

Allen J.F., 2001. On the Aggregation of Preferences in Engineering Design, In ASME Design Engineering Technical Conferences, sept 9-12, 2001, Pittsburgh, USA/PA, Paper number DETC2001-DAC21015.

Belk R., 1974. An exploratory assessment of situational effects in buyer behavior. Journal of Marketing Research, 11, 156-163.

Belk R., 1975. Situational variables and consumer behavior. Journal of Consumer Research, 2, 157-164.

Ben-Akiva M., Lerman S.R., 1985. Discrete Choice Analysis: Theory and Application to Travel Demand, Cambridge, MA: MIT Press.

Benhamou F., Granvilliers L., 2006. Continuous and Interval Constraints (Chapter 16), In Handbook of Constraint Programming, Rossi F., van Beek P., Walsh T. editors, Elsevier B.V., 571-604.

Bensana E., Mulyanto T., Verfaillie G., 2000. Dealing with uncertainty design and configuration problems, In Workshop on Configuration 14th European Conference on Artificial Intelligence, Berlin, Germany.

Bergman E., 2000. Information appliances and beyond: interaction design for consumer products Morgan Kaufmann Publishers, San Francisco, USA/CA..

Bettman J.R., 1979. An Information Processing Theory of Consumer Choice, Reading, MA: Addison Wesley.

Bliek C., 1995. Set based hierarchical design: a constraint satisfaction problem, In Design Engineering Technical Conferences, ASME 1995, 437-446.

Canbaz B., Yannou B., Yvars P.-A., 2011. A New Framework for Collaborative Set-Based Design: Application to the Design Problem of a Hollow Cylindrical Cantilever Beam, In IDETC/DAC, August 28-31, Washington DC, USA.

Chenouard R., Sebastian P., Granvilliers L., 2007. Solving an air conditioning problem in an embodiment design context using constraint satisfaction techniques, In CP'2007, 13th International Conference on Principles and Practice of Constraint Programming, Providence, USA/RI, September 23-27.

Collavizza H., Delobel F., Rueher M., 1999. Comparing Partial Consistencies. Reliable Computing, 5 (3), 213-228.

Davis E., 1987. Constraint propagation with interval labels. Artificial Intelligence, 32 (3), 281-331.

Dickson P., 1982. Person-Situation: Segmentation's Missing Link. Journal of Marketing Research, 46 (4), 56-64.

Engel J.F., Blackwell R.D., Miniard P.W., 1990. Consumer Behavior, Chicago, IL: The Dryden Press.

Faltings B., 1994. Arc consistency for continuous variables. Artificial Intelligence, 65 (2), 363- 376.

Fernandez M.G., Seepersad C.C., Rosen D.W., Allen J.K., Mistree F., 2001. Utility-Based Decision Support for Selection in Engineering Design, In ASME Design Engineering Technical Conferences, Pittsburgh, USA/PA, sept 912, 2001, Paper number DETC2001-DAC21106.

Finch W.W., 1999. Set-based models of product platform design and manufacturing processes, In DETC'99: ASME 1999 Design Engineering Technical Conference, Las Vegas, USA, Paper number DETC99/DTM-8763.

Finch W.W., Ward A.C., 1997. A set-based system for eliminating infeasible designs in engineering problems dominated by uncertainty, In DETC'97: ASME / Design Engineering Technical Conference, Sacramento, California, Paper number DETC97/DTM-3886.

Garrido A., Onaindia E., Sapona O., 2008. Planning and scheduling in an e-learning environment. A constraintprogramming-based approach. Engineering Application of Artificial Intelligence, 21 (5), 733-743. 
Green M.G., Linsey J.S., Seepersad C.C., Wood K.L., 2006. Frontier design: a product usage context method, In ASME International Design Engineering Technical Conferences, Philadelphia, PA, USA.

Green M.G., Palani R.P.K., Wood K.L., 2004. Product usage context: improving customer needs gathering and design target setting, In ASME International Design Engineering Technical Conferences, Sept. 28-Oct. 2, Salt Lake City, UT, USA.

Green M.G., Tan J., Linsey J.S., Seepersad C.C., Wood K.L., 2005. Effects of product usages context on consumer product preferences, In ASME International Design Engineering Technical Conferences, Long Beach, CA., USA.

Green P.E., Carroll J.D., Goldberg S.M., 1981. A general approach to product design optimization versus conjoint analysis. Journal of Marketing, 45, 17-37.

Green P.E., Srinivasan V., 1978. Conjoint Analysis in Consumer Research: Issues and Outlook. Journal of Consumer Research, 5, 103-123.

Greene D.L., 2001. TAFV alternative fuels and vehicles choice model documentation, Oak Ridge National Laboratory, Center for Transportation Analysis.

He L., Chen W., Hoyle C., Yannou B., 2012. Choice modeling for usage context-based design. Journal of Mechanical Design, 134 (3), DOI: 10.1115/1.4005860.

He L., Hoyle C., Chen W., Wang J., Yannou B., 2010. A framework for choice modeling in usage context based design, In IDETC/DAC: ASME International Design Engineering Technical Conferences \& Computers and Information in Engineering Conferences / Design Automation Conference, August 15-18, Montreal, Canada.

Hoffmann J., Mathieu J.-P., Roehrich G., Mallein P., 2008. Evaluating design as a system of representations: the moderating role of representation towards the use of new technologies, In International Product Development Management Conference, Hamburg, Germany.

Hoffmann J., Roehrich G., Mathieu J.-P., 2006. The role of usage and usage intention anticipations in a new product appraisal (Le rôle de l'anticipation d'usage et de l'intention d'usage dans l'évaluation d'un nouveau produit), In International Conference of the French Marketing Association (Congrès International de l'Association Française de Marketing), Nantes, France.

Holbrook M.B., Hirschman E.C., 1982. The experiential aspects of consumption: consumer fantasies, feelings and fun. Journal of Consumer Research, 9 (2), 132-140.

Howard J.A., Sheth J., 1969. The Theory of Buyer Behaviour John Wiley.

Hoyle C., Chen W., Wang N., Koppelman F., 2010. Integrated Bayesian Hierarchical Choice Modeling to Capture Heterogeneous Preferences in Engineering System Design. Journal of Mechanical Design, 132 (12), DOI: 10.1115/1.4002972, 2010.

Huffman C., Houston M.J., 1993. Goal-oriented experiences and the development of knowledge. Journal of Consumer Research, 20 (2), 190-207.

IBM, 2009. IBM Ilog Solver Reference Manual IBM ed.

Kennedy M.N., Harmon K., Minnock E., 2008. Ready, Set, Dominate: Implement Toyota's Set-based Learning for Developing Products and Nobody Can Catch You Oaklea Press.

Koppelman, F., Bhat, C., Sethi, V., and Williams, B., 2006, A Self Instructing Course in Mode Choice Modeling: Multinomial and Nested Logit Models, U.S. Department of Transportation, Federal Transit Administration.

Kumar D., Hoyle C., Chen W., 2007. Incorporating customer preferences and market trends in vehicle package design, In IDETC/DAC: ASME International Design Engineering Technical Conferences \& Computers and Information in Engineering Conferences / Design Automation Conference, Sept. 4-7, Las Vegas, Nevada, USA.

Kumar D., Hoyle C., Chen W., Wang N., Gomez-Levi G., Koppelman F., 2009. A Hierarchical Choice Modelling Approach for Incorporating Customer Preferences in Vehicle Package Design. International Journal of Product Development, 8 (3), 228-251.

Lebbah Y., Lhomme O., 2002. Accelerating filtering techniques for numeric CSPs. Artificial Intelligence, 139 (1), 109-132.

Luo L., 2011. Product Line Design for Consumer Durables: An Integrated Marketing and Engineering Approach. Journal of Marketing Research, 48 (1), 128-139. 
Macworth A., 1977. Consistency on networks of relations. Artificial Intelligence, 8, 99-118.

McFadden D., 1974. Conditional Logit Analysis of Qualitative Choice Behavior, In Frontiers in Econometrics, Zarembka P. editors, New York: Academic Press, 105-142.

Messac A., Gupta S., Akbulut B., 1996. Linear Physical Programming: A New Approach to Multiple Objective Optimization. Transactions on Operational Research, 8, 39-59.

Messac A., Ismail-Yahaya A., Mattson C.A., 2003. The Normalized Normal Constraint Method for Generating the Pareto Frontier. Structural and Multidisciplinary Optimization - Journal of the International Society of Structural and Multidisciplinary Optimization (ISSMO), 25 (2), 86-98.

Meyer Y., Yvars P.A., 2012. Optimization of a passive structure for active vibration isolation: an interval computation- and constraint-propagation-based approach. Engineering Optimization, 44 (12) , 1463-1489, DOI: 10.1080/0305215X.2011.652102.

Montanari U., 1974. Networks of constraints: fundamental properties and applications to picture processing. Information Sciences, 7, 95-132.

Moore R.E., 1966. Interval analysis, Englewood Cliffs, N.J.: Prentice-Hall.

Otto K., Antonsson E., 1993a. The Method of Imprecision Compared to Utility Theory for Design Selection Problems, In ASME/DTM '93: Design Theory and Methodology, Albuquerque, USA/NM, September 27-30, 167-173.

Otto K., Antonsson E., 1993b. Propagating Imprecise Engineering Design Constraints, In IEEE International Conference on Fuzzy Systems, Yokohama, Japan, 375-382.

Papalambros P.Y., 2002. The optimization paradigm in engineering design: promises and challenges. ComputerAided Design, 34 (12), 939-951.

Philips D., 1996. Anticipating the future: The role of consumption visions in consumer behavior, in Advances in Consumer Research, ed. Brucks M., MacInnis D.J., Vol. 24, 70-75: Provo, UT: Association for Consumer Research.

Prahalad C.K., Ramaswamy V., 2000. Co-opting customer competence. Harard Business Review, 78 (1), 79-87.

Qureshi A.J., Dantan J.-Y., Bruyere J., Bigot R., 2010. Set based robust design of mechanical systems using the quantifier constraint satisfaction algorithm. Engineering Applications of Artificial Intelligence, 23 (October 2010) (7), 1173-1186.

Ratneshwar S., L. W., 1993. The role of usage context in consumer choice: a problem-solving perspective. Advances in consumer research, 20, 377-382.

Ratneshwar S., Shocker A.D., 1991. Substitution in Use and the Role of Usage Context in Product Category Structures. Journal of Marketing Research, 28 (3), 281-295.

Reichenbacher T., 2003. Adaptive methods for mobile cartograph, In 21st International Cartographic Conference, 10-16 August, Durban, South Africa.

Santini D.J., Vyas A.D., 2005. Suggestions for a New Vehicle Choice Model Simulating Advanced Vehicles Introduction Decisions (AVID): Structure and Coefficients, Center for Transportation Analysis, Argonne National Laboratory.

Scott M.J., Antonsson E.K., 2000. Using Indifference Points in Engineering Decisions, In ASME/DETC2000/DTM, September 10-13, Baltimore, Maryland, USA.

Srivastava R.K., 1981. Usage-situational influences on perceptions of product-markets: theoretical and empirical issues. Advances in Consumer Research, 8, 106-111.

Stump G., Yukish M.A., Martin J.D., Simpson T.W., 2004. The ARL Trade Space Visualizer - An Engineering Decision-Making Tool, In 10th AIAA/ISSMO Multidisciplinary Analysis and Optimization Conference, Aug. 30 Sep. 1, Albany, NY.

Thurston D.L., 1991. A formal method for subjective design evaluation with multiple attributes. Research in engineering Design, 3, 105-122.

Thurston D.L., Liu T., 1991. Design Evaluation of Multiple Attributes Under Uncertainties. International Journal of Systems Automation - Research and Application (SARA), 1, 143-159. 
Thurston L.D., Carnahan J.V., 1992. Fuzzy ratings and utility analysis in preliminary design evaluation of multiple attributes. ASME Transactions of Mechanical Design, 114, 648-658.

Train, K. E., 2003, Discrete Choice Methods with Simulation, Cambridge University Press, Cambridge.

Tsang E., 1993. Foundations of Constraint Satisfaction, London and San Diego: Academic Press.

Vargas C., 1995. Modélisation du processus de conception en ingénierie des systèmes mécaniques. Mise en oeuvre basée sur le propagation de contraintes. Application à la conception d'une culasse automobile. PhD thesis. Ecole Normale Supérieure de Cachan.

Vargas C., Saucier A., Albert P., Yvars P.A., 1994. Knowledge modeling and constraint propagation in a computer aided design system, In Workshop notes Constraint Processing in CAD of the Third International Conference on Artificial Intelligence in Design, August, Lausanne, Switzerland.

Wang J., 2012. A usage coverage based approach for assessing product family design - Une méthode d'évaluation de la conception d'une famille de produits basée sur le modèle de couverture d'usages. Thèse de Doctorat. Ecole Centrale Paris, Laboratoire Génie Industriel.

Wang J., Yannou B., 2010. A market segmentation process based on usage context, In KEER2010: International Conference on Kansei Engineering and Emotion Research, March 2-4, Paris.

Wang J., Yannou B., Alizon F., Yvars P.-A., 2012. A Usage Coverage-Based Approach for Assessing Product Family Design. Engineering With Computers, DOI 10.1007/s00366-012-0262-1.

Ward A.C., 2007. Lean Product and Process Development, Cambridge, USA: The Lean Enterprise Institute Inc.

Ward A.C., Liker J.K., Sobek D.K., Cristiano J.J., 1994. Set-based concurrent engineering and Toyota, In DETC'94: ASME / Design Engineering Technical Conference, Sacramento, California, Paper number DETC94/DTM, 79-90.

Wassenaar H.J., Chen W., 2003. An approach to decision-based design with discrete choice analysis for demand modeling. Journal of Mechanical Design, 125 (3), 490-497, doi:Doi 10.1115/1.1587156.

Wood W.H., 2001. A view of design theory and methodology from the standpoint of design freedom, In ASME Design Engineering Technical Conferences, Pittsburgh, USA/PA, sept 9-12, 2001, Paper number DETC2001-DTM21717.

Yannou B., Chen W., Wang J., Hoyle C., Drayer M., Rianantsoa N., Alizon F., Mathieu J.-P., 2009. Usage Coverage Model For Choice Modeling: Principles, In IDETC/DAC: ASME International Design Engineering Technical Conferences \& Computers and Information in Engineering Conferences / Design Automation Conference, August 30 - September 02, San Diego, CA.

Yannou B., Hamdi A., 2004. Truss dimensioning with an uncertainty reduction paradigm, In International Design Conference, May 18-20, Dubrovnik, Croatia.

Yannou B., Harmel G., 2004. A comparative study of constraint programming techniques over intervals in preliminary design, In DETC/DAC: ASME Design Engineering Technical Conferences / Design Automation Conference, Sept. 28 - Oct. 2, Salt Lake City, Utah, USA, Paper number DETC2004/57152.

Yannou B., Harmel G., 2005. Use of Constraint Programming for Design, In Advances in Design, ElMaraghy H., ElMaraghy W. editors, Springer-Verlag, London, Chapter 12, 145-155.

Yannou B., Wang J., Yvars P.-A., 2010a. Computation of the usage contexts coverage of a jigsaw with CSP techniques, In IDETC/DAC: ASME International Design Engineering Technical Conferences \& Computers and Information in Engineering Conferences / Design Automation Conference, August 15-18, Montreal, Canada.

Yannou B., Wang J., Yvars P.-A., 2010b. Parameterization of a jigsaw and engineering equations for the simulation of its performances and usage scenario coverage indicators, Technical Document, http://www.lgi.ecp.fr/uploads/Recherche/Jigsaw_Technical_Document.pdf, Ecole Centrale Paris, Laboratoire Genie Industriel, May 17th 2010.

Yannou B., Yvars P.-A., Wang J., 2010c. Simulation of the usage coverage of a given product, In International Design Conference - Design 2010, May 17-20, Dubrovnik, Croatia.

Yvars P.A., 2008. Using constraint satisfaction for designing mechanical systems. International Journal on Interactive Design and Manufacturing (IJIDeM), 2 (3), 161-167. 